Article

\title{
From Cellulose, Shrimp and Crab Shells to Energy Storage EDLC Cells: The Study of Structural and Electrochemical Properties of Proton Conducting Chitosan-Based Biopolymer Blend Electrolytes
}

\author{
Shujahadeen B. Aziz ${ }^{1,2, *}$ (D), Muhamad. H. Hamsan ${ }^{3}$, Muaffaq M. Nofal ${ }^{4}\left(\mathbb{D}\right.$, Saro San $^{5}$, \\ Rebar T. Abdulwahid 1,6 (D), Salah Raza Saeed ${ }^{7}$, Mohamad A. Brza ${ }^{1,8}$, Mohd F. Z. Kadir ${ }^{9}$, \\ Sewara J. Mohammed ${ }^{10}$ and Shakhawan Al-Zangana ${ }^{11_{(D)}}$ \\ 1 Hameed Majid Advanced Polymeric Materials Research Lab., Department of Physics, College of Science, \\ University of Sulaimani, Qlyasan Street, Sulaimani 46001, Kurdistan Regional Government, Iraq; \\ rebar.abdulwahid@univsul.edu.iq (R.T.A.); mohamad.brza@gmail.com (M.A.B.) \\ 2 Department of Civil Engineering, College of Engineering, Komar University of Science and Technology, \\ Sulaimani 46001, Kurdistan Regional Government, Iraq \\ 3 Institute for Advanced Studies, University of Malaya, Kuala Lumpur 50603, Malaysia; \\ hafizhamsan93@gmail.com \\ 4 Department of Mathematics and General Sciences, Prince Sultan University, P. O. Box 66833, \\ Riyadh 11586, Saudi Arabia; muaffaqnofal@gmail.com \\ 5 Department of Physics and Astronomy, University of Missouri-Kansas City, MO 64110, USA; \\ ssawcc@mail.umkc.edu \\ 6 Department of Physics, College of Education, University of Sulaimani, Old Campus, \\ Sulaimani 46001, Kurdistan Regional Government, Iraq \\ 7 Charmo Research Center, Charmo University, Peshawa Street, Chamchamal, \\ Sulaimani 46001, Kurdistan Regional Government, Iraq; salah.saeed@charmouniversity.org \\ 8 Manufacturing and Materials Engineering Department, Faculty of Engineering, \\ International Islamic University of Malaysia, Kuala Lumpur 50603, Gombak, Malaysia \\ 9 Centre for Foundation Studies in Science, University of Malaya, Kuala Lumpur 50603, Malaysia; \\ mfzkadir@um.edu.my \\ 10 Department of Chemistry, College of Science, University of Sulaimani, Qlyasan Street, \\ Sulaimani 46001, Kurdistan Regional Government, Iraq; sewara.mohammed@univsul.edu.iq \\ 11 Department of Physics, College of Education, University of Garmyan, Kalar 46021, \\ Kurdistan Regional Government, Iraq; shakhawan.al-zangana@garmian.edu.krd \\ * Correspondence: shujahadeenaziz@gmail.com
}

Received: 17 June 2020; Accepted: 6 July 2020; Published: 9 July 2020

check for updates

\begin{abstract}
In this study, solid polymer blend electrolytes (SPBEs) based on chitosan (CS) and methylcellulose $(\mathrm{MC})$ incorporated with different concentrations of ammonium fluoride $\left(\mathrm{NH}_{4} \mathrm{~F}\right)$ salt were synthesized using a solution cast technique. Both Fourier transformation infrared spectroscopy (FTIR) and X-ray diffraction (XRD) results confirmed a strong interaction and dispersion of the amorphous region within the CS:MC system in the presence of $\mathrm{NH}_{4} \mathrm{~F}$. To gain better insights into the electrical properties of the samples, the results of electrochemical impedance spectroscopy (EIS) were analyzed by electrical equivalent circuit (EEC) modeling. The highest conductivity of $2.96 \times 10^{-3} \mathrm{~S} \mathrm{~cm}^{-1}$ was recorded for the sample incorporated with $40 \mathrm{wt} . \%$ of $\mathrm{NH}_{4} \mathrm{~F}$. Through transference number measurement (TNM) analysis, the fraction of ions was specified. The electrochemical stability of the electrolyte sample was found to be up to $2.3 \mathrm{~V}$ via the linear sweep voltammetry (LSV) study. The value of specific capacitance was determined to be around $58.3 \mathrm{~F} / \mathrm{g}$. The stability test showed that the electrical double layer capacitor (EDLC) system can be recharged and discharged for up to 100 cycles with an average specific capacitance of $64.1 \mathrm{~F} / \mathrm{g}$. The synthesized EDLC cell was found to
\end{abstract}


exhibit high efficiency (90\%). In the 1st cycle, the values of internal resistance, energy density and power density of the EDLC cell were determined to be $65 \Omega, 9.3 \mathrm{Wh} / \mathrm{kg}$ and $1282 \mathrm{~W} / \mathrm{kg}$, respectively.

Keywords: polymer blend; XRD and FTIR; impedance study; TNM and LSV; CV and EDLC

\section{Introduction}

Energy storage devices, such as lithium batteries, supercapacitors and fuel cells using liquid electrolytes, have attracted significant attention in recent years, owing to their ionic nature. However, there are several issues that still need to be solved, such as the release of harmful gases, the lack of safety and corrosive action [1]. It is difficult to use a harmless liquid in energy storage devices without any drawbacks. Designing a desirable device with a proper size and shape that fits liquid electrolytes is challenging [2]. This encourages scientists and researchers to work on the development of a safe and efficient solid polymer electrolyte (SPE). SPEs can provide satisfactory thermal stability, low weight, high flexibility, cost effectiveness and easy handling [3]. On the other hand, the harmful effects of plastic wastes on the environment are recognized to cause global warming and water pollution. Therefore, there is a special interest in the development of biodegradable and biocompatible natural polymers as SPEs [4]. This is due to their abundance, biocompatibility, biodegradability and cost effectiveness [5]. These favorable properties have made scientific circles extensively utilize natural polymers in polymer electrolyte-based devices [6]. There are many natural polymers, including starch, CS, carboxymethyl cellulose (CMC), MC and rubber that can be used in the synthesis of SPEs [5,6]. In this study, CS and MC were used as natural polymers. CS is often extracted from crustaceans (crabs, lobsters, crayfish, shrimp, krill and barnacles) and has a chemical structure of $\beta$-(1 $\rightarrow 4) 2$-amino-2-deoxy-D-glucose-(D-glucosamine) [4], while MC is obtained from mixing alkali-based cellulose with methyl chloride. The chemical structure of MC comprises a 1,4 glycosidic bond [7]. The reduced ion mobility in SPE matrices has led numerous research groups to develop different approaches that have improved the ambient conductivity. Two common approaches which are widely addressed are the blending of two polymers and using a variety of salts [8-13]. Polymer blending is regarded as a promising technique to upgrade the properties of individual polymer constituents. Many new and enhanced characteristics can be achieved through the polymer blending technique, such as relatively high ionic conductivity, flexibility, transference number and thermal stability [14]. Recently, polymer electrolytes assembled from biopolymer attracted the attention of many research groups due to their availability for a wide range of applications in electrochemical devices [2-4,8,10-12]. Both CS and MC are known to contain functional groups with lone pair electrons that assist ion transport within their matrixes. This is due to the fact that the lone pair electrons within their structure can serve as complexation sites for the ions.

The preparation of proton $\left(\mathrm{H}^{+}\right)$-conducting SPEs is usually involves mixing strong inorganic acids or ammonium salts. For instance, sulfuric acid $\left(\mathrm{H}_{2} \mathrm{SO}_{4}\right)$ and phosphoric acid $\left(\mathrm{H}_{3} \mathrm{PO}_{4}\right)$ are the two commonly used inorganic acids. However, the main drawback of these inorganic acids is their chemical degradation when mixed with SPEs, which leads to incompatibility with practical applications [15]. Therefore, the ammonium salts are usually utilized to obtain a proton-conducting SPE with a relatively high ionic conductivity and thermal stability. The continuous interactions of the charge carriers with the available functional group then generates motion of the polymer chain segments and thus makes the polymer more conductive [16]. Radha et al. have documented a conductivity value of $6.9 \times 10^{-6} \mathrm{~S} / \mathrm{cm}$ for the polyvinyl alcohol (PVA)-ammonium fluoride $\left(\mathrm{NH}_{4} \mathrm{~F}\right)$ system [17]. Additionally, the enhancement in the dielectric behavior of PVA with the presence of $\mathrm{NH}_{4} \mathrm{~F}$ was also addressed. Another research study has also recently reported a relatively high conductivity of $6.40 \times 10^{-7} \mathrm{~S} / \mathrm{cm}$ for the $\mathrm{MC}-\mathrm{NH}_{4} \mathrm{~F}$ system at room temperature [5]. Doping $\mathrm{NH}_{4} \mathrm{~F}$ into the $\mathrm{CS}$-dextran system also resulted in a high value of conductivity, up to $10^{-3} \mathrm{~S} / \mathrm{cm}[18]$. 
Electrical double layer capacitors (EDLCs) are one of the promising electrochemical energy storage devices that fulfill the requirements of high power application with fast charge-discharge cycles. The energy storage mechanism in these devices involves charge accumulation on the carbon electrode surface at the interfacial region in the form of potential energy [19]. EDLCs feature a fantastic high power density, long cycle life, fast charge-discharge rate and simplistic fabrication procedure [20]. In EDLC devices, various types of carbon have been used as electrode materials, for instance, graphite [21], aerogel [22], carbon nanofibers [23] and activated carbon [24]. The most used one is activated carbon, which is almost an ideal active material that is defined by a high surface area, satisfactory electronic conductivity and cost effectiveness [25]. Based on an earlier study, ammonium salts have been shown to exhibit reasonable proton donor behavior if incorporated into polymer matrices [26]. In order to enhance the performance of biodegradable-based EDLC devices to meet the industrial level, various polymer blended electrolytes with different dopant salts were studied. An extensive literature survey revealed that the effect of $\mathrm{NH}_{4} \mathrm{~F}$ salt concentration on the conductivity of a CS:MC blended system and its use in EDLC devices had not already been investigated. Thus, for this work, firstly, systems of CS:MC incorporated with various concentrations of $\mathrm{NH}_{4} \mathrm{~F}$ were examined through electrical and structural analyses. Then, the relatively highest conducting SPBE film was utilized as the electrode separator in an EDLC device application.

\section{Experimental Part}

\subsection{Materials and Sample Preparation}

In this work, CS with a relatively high molecular mass of around 310,000 to 375,000 g/mol was used, along with $\mathrm{MC}$ and $\mathrm{NH}_{4} \mathrm{~F}$ in the fabricating of SPBE systems. All the materials were supplied by Sigma-Aldrich Corporation (Missouri, MO, USA). Firstly, for the preparation of CS:MC polymer blend electrolytes, two separated solutions of CS and MC with percentages of $70 \mathrm{wt} . \%$ and $30 \mathrm{wt} . \%$, respectively, were dissolved in $40 \mathrm{~mL}$ of $1 \%$ acetic acid. They were stirred for $3 \mathrm{hrs}$ at room temperature. Based on previous work [27], this ratio of CS and MC was shown to be optimal in the preparation of CS:MC polymer blend electrolytes. Then, both solutions of CS and MC were mixed with continuous stirring for $2 \mathrm{hrs}$ in order to obtain a final homogeneous blended solution. Subsequently, with continuous stirring, different portions of $\mathrm{NH}_{4} \mathrm{~F}$, ranging from 10 to $40 \mathrm{wt} . \%$ in steps of $10 \mathrm{wt} . \%$, were added separately to a series of blended solutions to obtain CS:MC: $\mathrm{NH}_{4} \mathrm{~F}$ electrolytes. The final solutions were then poured into Petri dishes to cast films at ambient temperature. For further drying, the formed films were then transferred into a desiccator to achieve solvent-free films. The obtained polymer blend electrolyte samples were coded as CMCF0, CMCF1, CMCF2, CMCF3 and CMCF4 for CS:MC doped with 0, 10, 20, 30 and 40 wt. $\%$ of $\mathrm{NH}_{4} \mathrm{~F}$, respectively.

\subsection{Structural and Impedance Analyses}

XRD measurements were performed to study the structural properties of the samples, using a Siemens D5000 X-ray diffractometer (1.5406 ̊) (Bruker AXS GmbH, Berlin, Germany). The acquisition process comprised scanning the $2 \theta$ angle continuously from $5^{\circ}$ to $80^{\circ}$ (resolution $=0.1^{\circ}$ ). FTIR $($ FT-IR, Spotlight 400 Perkin-Elmer spectrometer, Waltham, MA, USA) was conducted in the range 450 to $4000 \mathrm{~cm}^{-1}$ with a $1 \mathrm{~cm}^{-1}$ resolution. Electrical properties of the samples were studied by means of EIS (HIOKI 3532-50 LCR Hi-TESTER) (Hioki, Nagano, Japan) in the frequency range of $50 \mathrm{~Hz}$ to $5 \mathrm{MHz}$. For the purpose of electrical characterizations, the samples were sandwiched between two stainless steel electrodes. Based on the results obtained in EIS measurements and the sample dimensions, the conductivities of the samples were determined, using the following equation:

$$
\sigma_{d c}=\left(\frac{1}{R_{b}}\right) \times\left(\frac{t}{A}\right)
$$

where $R_{b}$ is the bulk resistance of the sample, $t$ is the film thickness and $A$ is the surface area of the film. 


\subsection{Transference Number Measurement (TNM) and Linear Sweep Voltammetry (LSV) Studies}

To use polymer blend electrolytes in applications, it is important to study their TNM and LSV measurements. Through TNM measurements, one can verify the ion dominancy in the conduction process. LSV measurements were used to investigate the sample electrolytes' potential stability. The TNM measurements were performed by using a V \& A Instrument DP3003 digital DC power supply with $0.20 \mathrm{~V}$ (V \& A Instrument, Shanghai, China). LSV measurements were also carried out by using a Digi-IVY DY2300 Potentiostat at a sweep rate of $50 \mathrm{mV} \mathrm{s}^{-1}$ (Neware, Shenzhen, China). The cell used in both TNM and LSV measurements was composed of two stainless steel (SS) disks and the highest conducting SPBE film. The cell was then mounted in a Teflon holder, as shown in Figure 1.

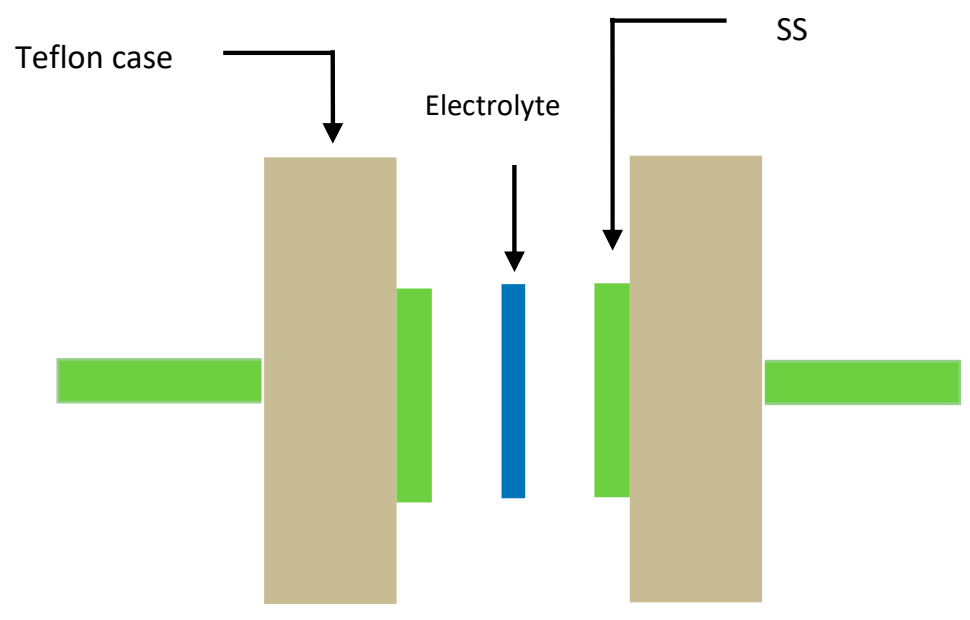

Figure 1. Schematic appearance of the cell used for the LSV and TNM measurements.

\subsection{EDLC Preparation}

For the fabrication of an EDLC device, electrodes composed of polyvinylidene fluoride (PVdF), activated carbon and carbon black materials, were used. Under medium stirring, $0.5 \mathrm{~g}$ of PVdF was dissolved in $15 \mathrm{~mL}$ of N-methyl pyrrolidone (NMP) to obtain an NMP-PVdF solution. The activated carbon and carbon black materials were dry mixed for $15 \mathrm{~min}$ by using a planetary ball miller (XQM-0.4) with a rotational speed of $500 \mathrm{r} / \mathrm{min}$. The obtained powders were composed of $3.25 \mathrm{~g}$ and $0.25 \mathrm{~g}$ of activated carbon and carbon black materials, respectively. The powder was then poured into the NMP-PVdF solution and stirred to dissolve completely. Then, the mixture was cast on an aluminum foil with a doctor blade technique to obtain a thick black solution. Subsequently, the folded solution was heated at $60^{\circ} \mathrm{C}$ in an oven for a certain time to obtain a dried state. The obtained dried bulk electrode was then cut into a circle with an area of $2.01 \mathrm{~cm}^{2}$. In the final step of the EDLC cell preparation, the relatively high conducting electrode film was sandwiched between two carbon electrodes and packed in CR2032 coin cells. The fabricated EDLC cell was then fixed over the Teflon holder for further testing. Cyclic voltammetry of the EDLC was performed at $10 \mathrm{mV} \mathrm{s}^{-1}$ and charged up to $0.90 \mathrm{~V}$, by using a Digi-IVY DY2300 Potentiostat (Neware, Shenzhen, China). Furthermore, the charge-discharge profiles of the EDLC were also examined using a Neware battery cycler (Neware, Shenzhen, China) with a current density of $0.2 \mathrm{~mA} \mathrm{~cm}^{-2}$.

\section{Result and Discussion}

\subsection{XRD and FTIR Study}

Figure 2 shows the XRD pattern of the pure and doped CM:MC samples. Previous studies have illustrated that pure MC displays broad humps and several weak peaks at $2 \theta=8^{\circ}$ and $21^{\circ}$ [28]. It has also been revealed that CS in its pure state, which has a predominant crystalline phase, is characterized by two obvious peaks at $14.50^{\circ}$ and $20.90^{\circ}$ as a result of inter- and intra-hydrogen bonding [29]. It is 
obvious in Figure 2a that the XRD peaks due to pure CS almost disappeared and only a hump can be seen. This indicates that the technique of polymer blending is a novel approach to overcome the crystalline phases. This is due to the formation of hydrogen bonding between MC and CS matrices. It is well defined that hydrogen bonding is based on the interaction between electron-deficient hydrogen and a high electron density region. In fact, hydrogen bonding (H-bonding), as an intermolecular interaction, can be expressed as $\mathrm{X}-\mathrm{H} \ldots \mathrm{Y}$, where $\mathrm{X}$ and $\mathrm{Y}$ are electronegative elements and $\mathrm{Y}$ possesses one or more lone electron pairs; in other words, $\mathrm{X}$ and $\mathrm{Y}$ are $\mathrm{F}, \mathrm{O}$ and $\mathrm{N}$ atoms, respectively [30]. It is evident from the molecular structure of MC (see Figure 3) that the monomer of MC contains $\mathrm{O}$ atoms, which enables it to build H-bonding. Clearly, hydrogen bonding as a secondary force is much weaker than the primary bond within the molecules, such as covalent bonds and other polar bonds, but far stronger than the van der Waals interaction [30]. It is notable from Figure 3a that about six hydrogen bonds can be formed between CS monomers; meanwhile, only three intermolecular hydrogen bonds can be developed between the $\mathrm{CH}$ and $\mathrm{MC}$ monomer, as depicted in Figure $3 \mathrm{~b}$. Therefore, the blended samples showed a smaller number of hydrogen bonding sites, which resulted in the reduction of the degree of crystallinity. The XRD peak broadness of the CS:MC blend sample pinpoints that the inter-chain spacing in the blended sample became larger than that of the individual polymers. The expanded inter-chain spacing in the blend simplifies the dipole reorientation to the applied field due to high amorphous content. The addition of $\mathrm{NH}_{4} \mathrm{~F}$ to the blend electrolytes (BEs) caused a clear reduction in the intensity of XRD peaks. Interestingly, upon the addition of $40 \mathrm{wt} . \%$ of $\mathrm{NH}_{4} \mathrm{~F}$, the lowest peak intensity was recorded. It is evidenced that the broad peak at $20.25^{\circ}$ (see Figure 2c) emphasizes the amorphous nature of the system. The characteristic feature of the amorphous nature of a polymer body is a broad peak in the form of a hump. Increasing salt in such a polymer system caused a relative reduction in the intensity of the broad peak between $11^{\circ}$ and $27.21^{\circ}$, thus increasing the amorphous structure of the BE system [26]. Therefore, the XRD pattern can certainly be used to show the amorphous characteristic of the samples, which was reflected in the gradual decrease in intensity with peak broadening due to the addition of $\mathrm{NH}_{4} \mathrm{~F}$ salt. It is also distinct that the dissimilarity in the intensity and sharpness of the XRD peaks of the polymer electrolytes after salt addition can be a good confirmation of strong interactions between the polymer and the inorganic salt [29].

FTIR is considered as an effective technique to deal with a new compound, in terms of both structure and composition, that forms during a chemical reaction. The extent of interaction between CS and MC in the BPE system was confirmed via the FTIR technique. Figure 4a-c shows the FTIR spectra of CS:MC biopolymer electrolytes in the wave number range of $4000-890 \mathrm{~cm}^{-1}$. It is motivating to observe both position shifting and intensity variation of the bands, which are considered as evidence of the existence of particular functional groups in pure CS:MC and CS:MC: $\mathrm{NH}_{4} \mathrm{~F}$ electrolyte systems. A more important observation is the confirmation of the presence of heteroatoms (e.g., $\mathrm{O}$ and $\mathrm{N}$ ) with lone pair electrons in a desired fabricated polymer host as electrolytes [31]. The appearance of a strong peak at around $2900 \mathrm{~cm}^{-1}$ is ascribed to the C-H stretching modes, as shown in Figure 4c [32,33], and its intensity decreased with rising salt concentration. It is also seen from the same figure that the CS polymer is characterized by a single $-\mathrm{NH}_{2}$ group and a couple of $-\mathrm{OH}$ groups in the repeating unit [34]. The doping process substantially affected the -OH stretching broad peak at $3359 \mathrm{~cm}^{-1}$ in Figure 4c [32]. The strong interaction between dopant salt and the CS:MC host blended polymer can be identified from both peak shifting and intensity changes. Based on earlier work [34], the presence of vibrational frequency peaks of $-\mathrm{NH}_{2}, \mathrm{O}=\mathrm{C}-\mathrm{NHR}$ and $-\mathrm{OH}$ are considered as the characteristic FTIR spectra of MC and CS polymers. It is clear from Figure $4 \mathrm{~b}$ that the shifting occurred towards lower wave numbers in the bands of amino $\mathrm{NH}_{2}, \mathrm{O}=\mathrm{C}-\mathrm{NHR}$ and $\mathrm{OH}$ groups, confirming a strong interaction between the $\mathrm{NH}_{4} \mathrm{~F}$ dopant salt and the CS:MC host blended polymer. 

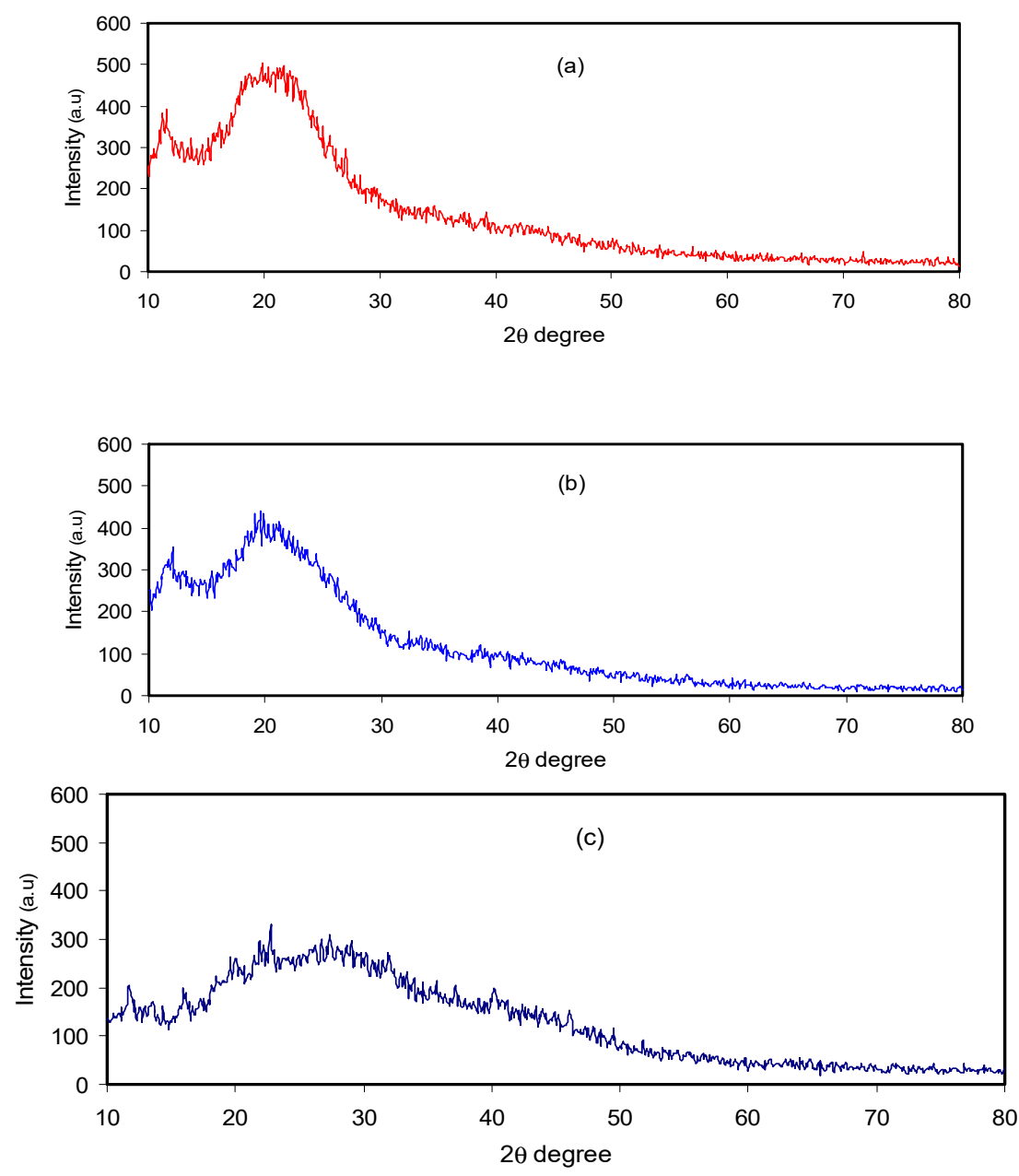

Figure 2. XRD pattern for (a) pure CS:MC, (b) CMCF2 and (c) CMCF4 blend electrolytes.

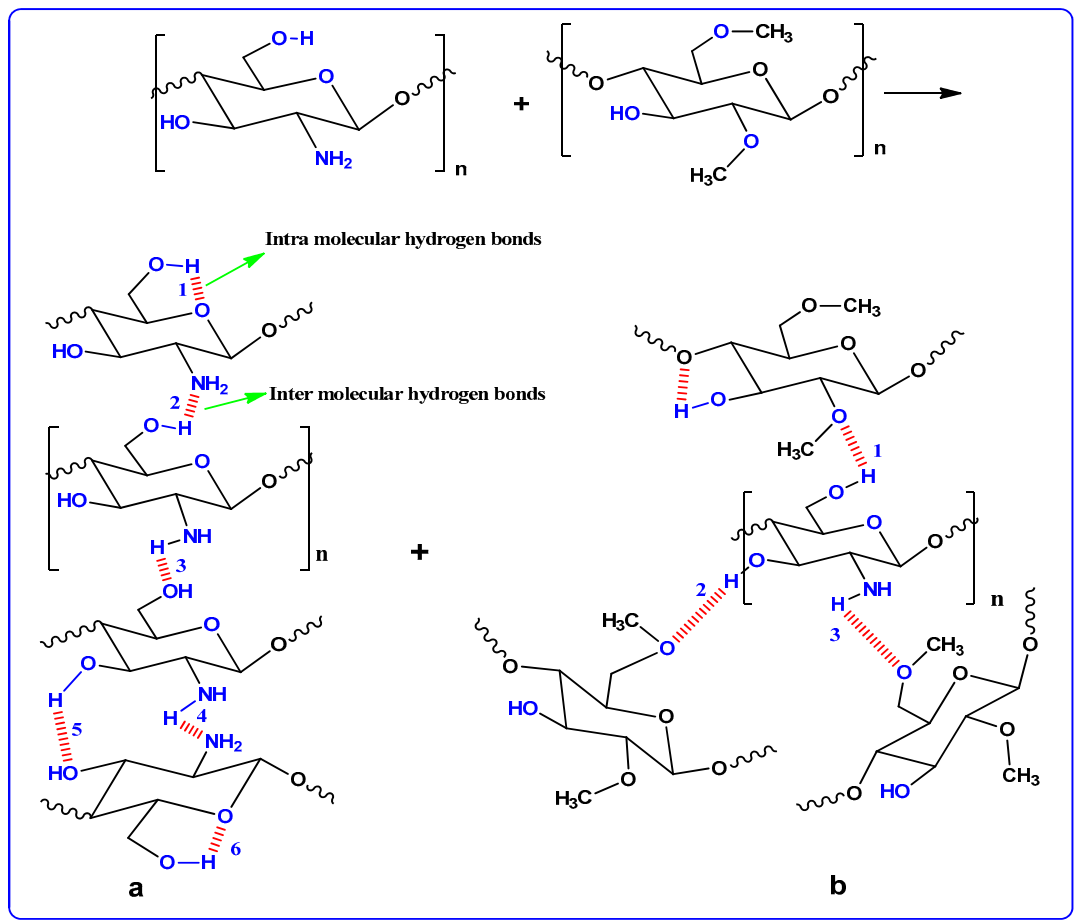

Figure 3. CS and MC polymer hydrogen bonding presentation; (a) hydrogen bonding through CS polymer and (b) hydrogen bonding CS:MC polymer blends. 

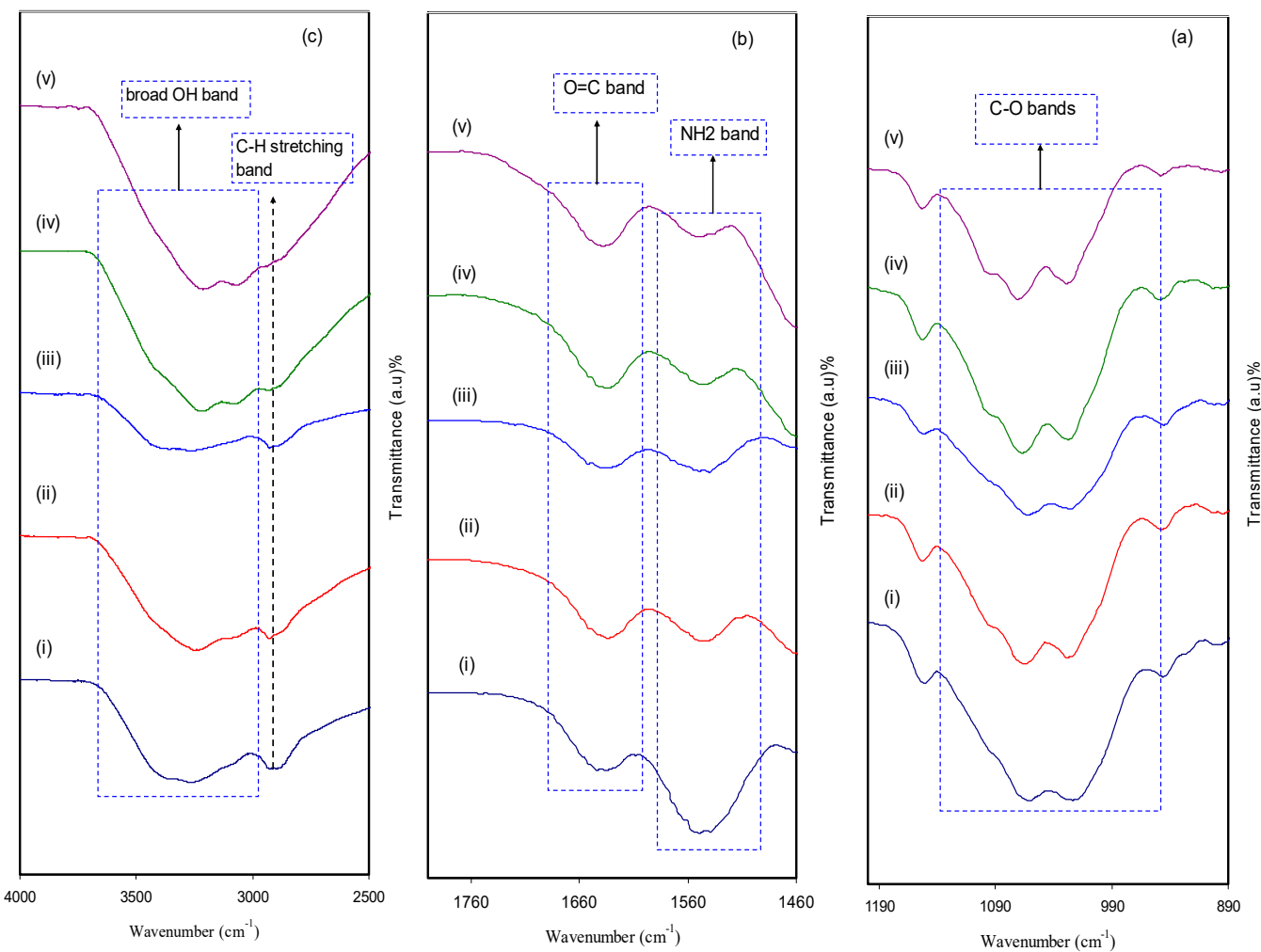

Figure 4. FTIR spectrum of (i) CMCF0, (ii) CMCF1, (iii) CMCF2, (iv) CMCF3 and (v) CMCF4 in the range (a) $890 \mathrm{~cm}^{-1}$ to $1190 \mathrm{~cm}^{-1}$, (b) $1460 \mathrm{~cm}^{-1}$ to $1760 \mathrm{~cm}^{-1}$ and (c) $2500 \mathrm{~cm}^{-1}$ to $4000 \mathrm{~cm}^{-1}$.

In Figure 4a, a peak at $1055 \mathrm{~cm}^{-1}$ appeared as a result of the antisymmetric stretching of an asymmetric oxygen bridge in the cyclohexane ring and a range from 1150 to $1000 \mathrm{~cm}^{-1}$ is attributed to the C-O-C bond [28]. It is observable that the intensity of the peaks decreased and to some extent shifting occurred as a consequence of the increment of $\mathrm{NH}_{4} \mathrm{~F}$ concentration. These certify that there is a strong interaction between the polymer body and amine salt via coordination bonds and thus confirms the complexation [35]. The addition of $\mathrm{NH}_{4} \mathrm{~F}$ salt provides cations that attract oxygen atoms at the $\mathrm{C}-\mathrm{O}-\mathrm{C}$ ether group in the identical polymer to produce polymer salt complexes [28]. In the current polymer salt system, the $\mathrm{NH}_{4}^{+}$ion from $\mathrm{NH}_{4} \mathrm{~F}$ coordinates to both the $\mathrm{O}$ atom of the ether group and the hydroxyl group in the CS and MC host polymer blend. These interactions prove the occurrence of protonation in the present electrolytes. It is clearly verified in the shifting of hydroxyl, ether, $\mathrm{C}=\mathrm{O}$ and $-\mathrm{NH}_{2}[5]$.

\subsection{Impedance Study}

The impedance spectra of the blend electrolyte films at ambient temperature are shown in Figure $5 \mathrm{a}-\mathrm{d}$. The semicircle at the high frequency region can be related to the parallel combination of the bulk electrolyte resistance $\left(\mathrm{R}_{\mathrm{E}}\right)$ and the bulk electrolyte capacitance $\left(\mathrm{C}_{\mathrm{E}}\right)$, owing to the migration process of proton ions and the immobilized state of polymer chains, respectively. Interestingly, the semicircle diameter was lessened with increasing salt concentration. This implies that the relaxation of ions occurred at different times [36]. The electrode/electrolyte capacitance $\left(\mathrm{C}_{\mathrm{EE}}\right)$ produced by the accumulated double-layer ions at the electrode/electrolyte interface (i.e., the low frequency spike region) is represented by another capacitor in series with the parallel combination of a resistor and capacitor corresponding to the high frequency semicircle. The schematic illustration of EEC for Figure $5 a, b$ is shown in Figure 6. To confirm our interpretation, the experimental impedance data were simulated with EECs, as can be seen in Figure 7. It is worth noting that at a high frequency region, the semicircle completely disappeared for 30 and $40 \mathrm{wt} . \%$ of $\mathrm{NH}_{4} \mathrm{~F}$ salt concentrations, as clearly shown in Figure $5 \mathrm{c}, \mathrm{d}$. 
This suggested that only the resistive component of the obtained impedance spectra is responded to by the polymer host body [27]. In this case, the resistor of the blend electrolyte film in series with the capacitor of the double-layer capacitances represents the electrical behavior of the system. The conductivity improvement upon the addition of $40 \mathrm{wt} . \%$ of $\mathrm{NH}_{4} \mathrm{~F}$ can be attributed to the increase in the number of mobile charge carriers. Moreover, the amorphous nature of the polymer electrolyte could have a vital role. Consequently, it results in an inferior energy barrier and facilitates the ion transport [35]. It is self-evident that the ionic conductivity of an electrolyte depends on both the number and mobility of ions, as can be seen from the following equation [37]:

$$
\sigma=\sum \eta q \mu
$$

where the carrier density is denoted as $\eta$, elementary charge is symbolized by $q$ and $\mu$ is the mobility. The literature confirmed that in a polymer-ammonium salt system, the charge-carrying species is an $\mathrm{H}^{+}$ion that is offered by an ammonium ion [27]. The most general theory of proton conduction is structure diffusion, which is known as the Grotthuss mechanism, where ion exchanging occurs between the complexed sites [38]. Proton conduction by the Grotthus mechanism states that protons jump over the complexing sites, leading to the creation of a vacant site followed by reorientation to occupy the vacant site [27]. Equation (1) was used to calculate the DC conductivity of the pure CS:MC and CS:MC: $\mathrm{NH}_{4} \mathrm{~F}$ electrolyte samples at room temperature. Table 1 lists the DC conductivities of the samples. It is noteworthy that the DC conductivity increased from $7.16 \times 10^{-10} \mathrm{~S} \mathrm{~cm}^{-1}$ for pure CS:MC to $7.34 \times 10^{-4} \mathrm{~S} \mathrm{~cm}^{-1}$ for CS:MC incorporated with $40 \mathrm{wt} . \%$ of $\mathrm{NH}_{4} \mathrm{~F}$. Previous studies have confirmed that polymer electrolytes with high DC conductivity, ranging from $10^{-5}$ to $10^{-3} \mathrm{~S} \mathrm{~cm}^{-1}$, can be crucial for electrochemical device applications, including batteries and EDLCs.
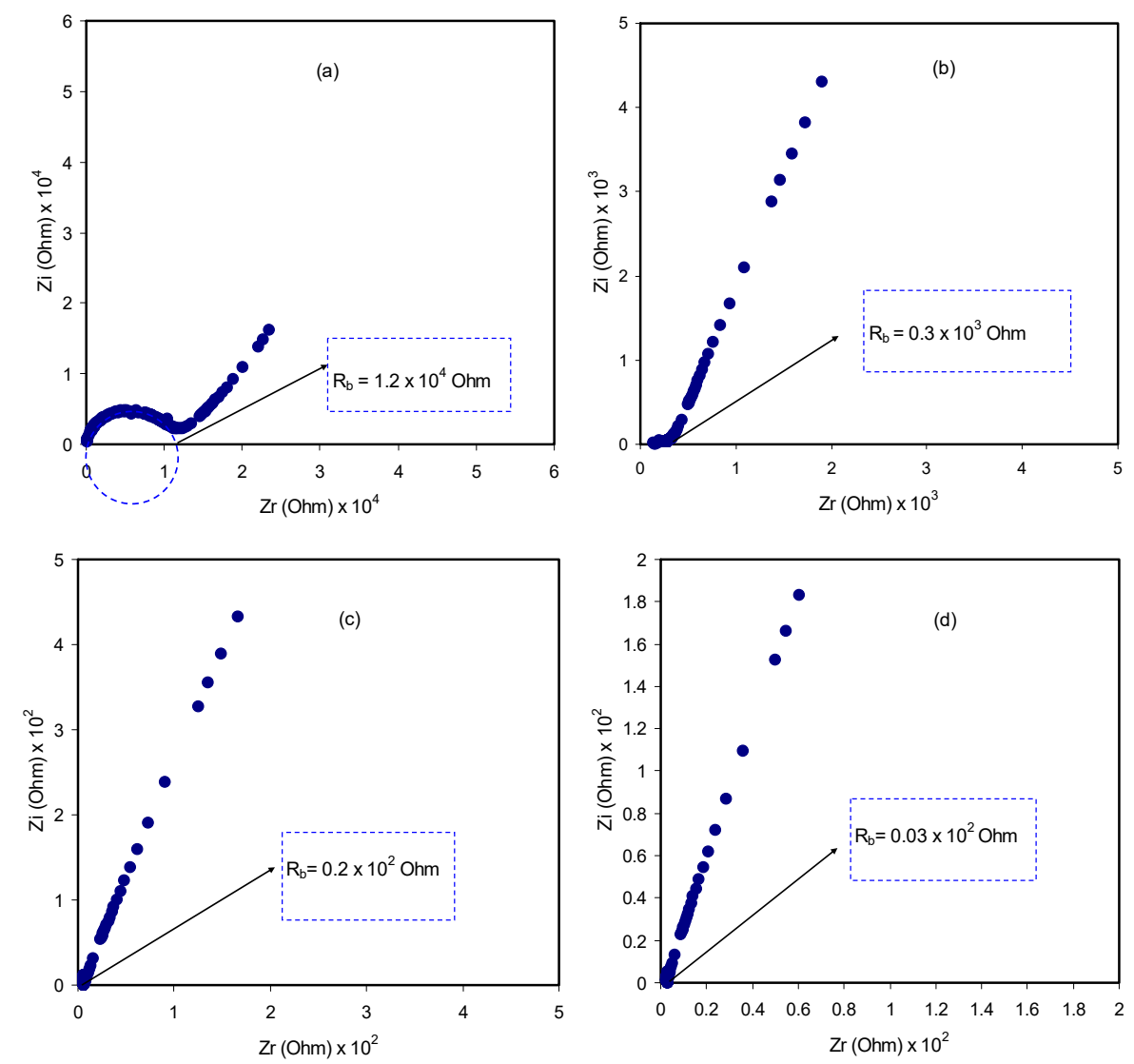

Figure 5. Impedance plots of (a) CMCF1, (b) CMCF2, (c) CMCF3 and (d) CMCF4 blended films at ambient temperature. 


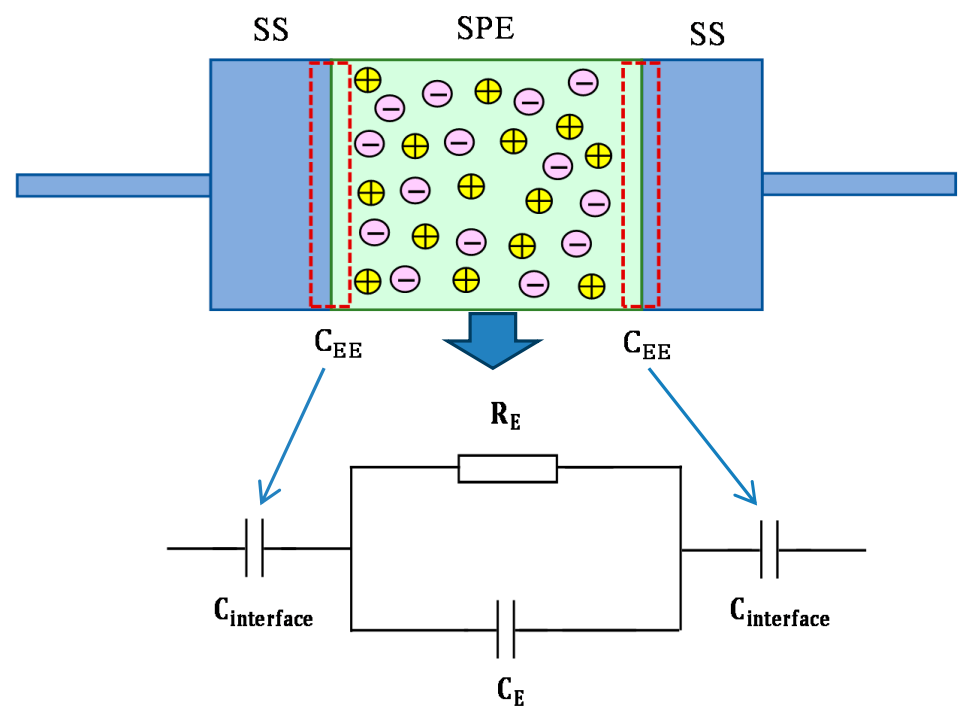

Figure 6. Schematic illustration of electrical equivalent circuits (EECs) for impedance plots consisting of a high-frequency semicircle and low-frequency tails.
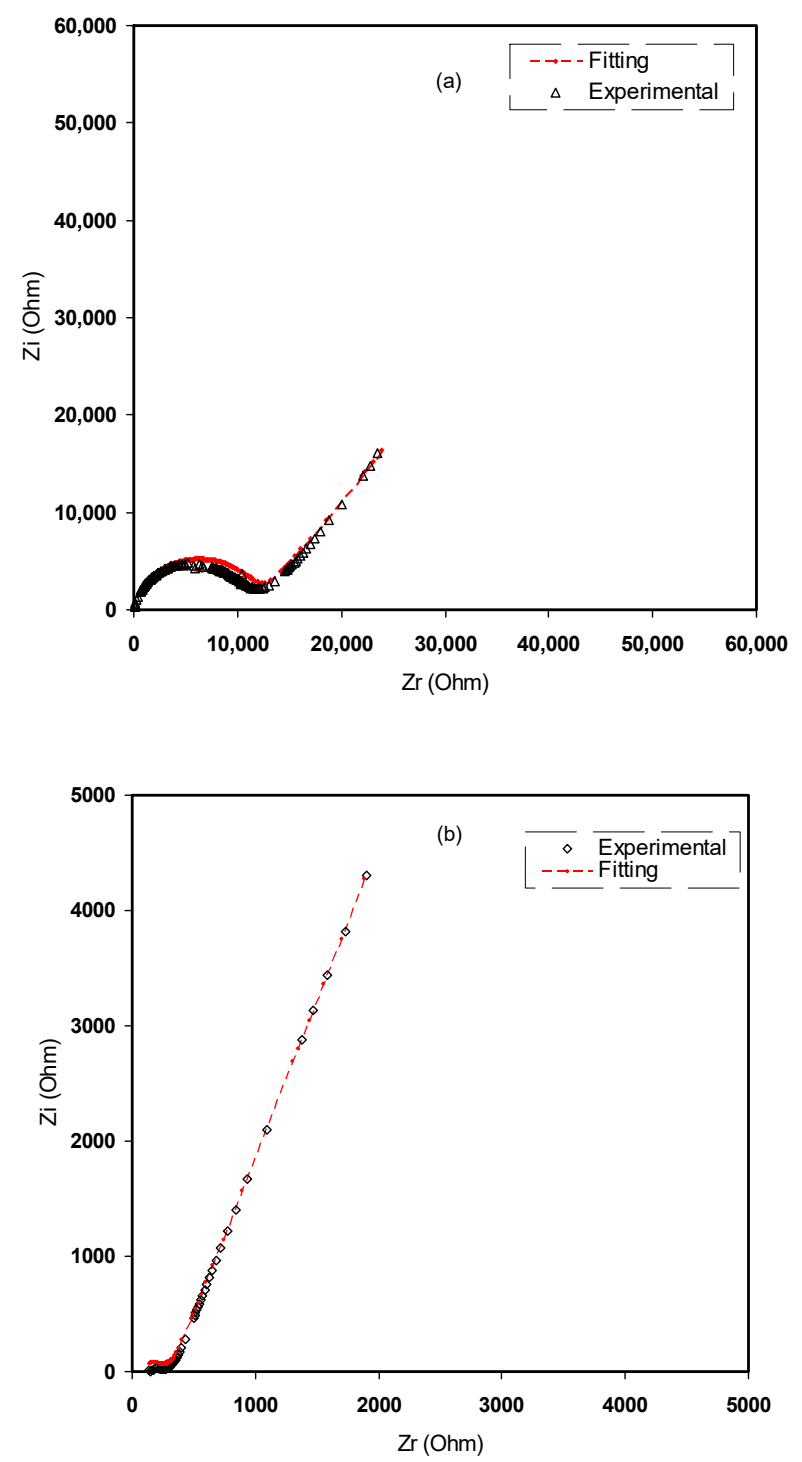

Figure 7. Cont. 

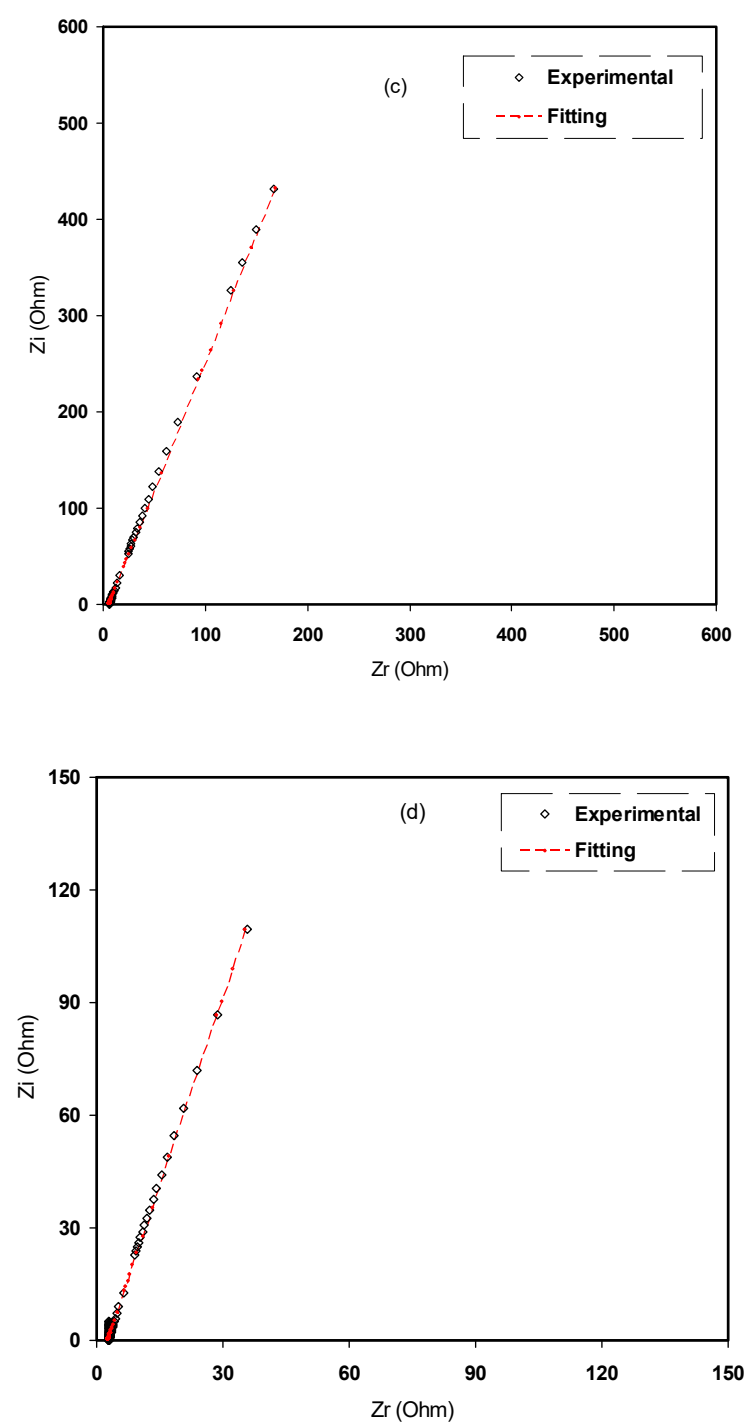

Figure 7. Experimental impedance and EEC fitting plots for (a) CMCF1, (b) CMCF2, (c) CMCF3 and (d) CMCF4 blended films at ambient temperature.

Table 1. DC conductivity for pure CS:MC and blend electrolyte films at room temperature.

\begin{tabular}{cc}
\hline Sample Designation & DC Conductivity $\left(\mathbf{S ~ c m}^{\mathbf{- 1}}\right)$ \\
\hline CMCF1 & $8.37 \times 10^{-10}$ \\
CMCF1 & $7.42 \times 10^{-7}$ \\
CMCF2 & $2.96 \times 10^{-5}$ \\
CMCF3 & $4.45 \times 10^{-4}$ \\
CMCF4 & $2.96 \times 10^{-3}$ \\
\hline
\end{tabular}

From the fitting and analysis of experimental spectra using the EEC technique, one can easily deal with the mechanism of the system under study [39]. The experimental impedance plots with EEC modeling for all the electrolyte samples are shown in Figure 7a-d. This model guides us to calculate and understand the electrical properties of solid-based electrolyte polymers. A three-component equivalent circuit reflects the experimental impedance plots. To be precise, the three principal elements are ZCPE1 (constant phase, electrode/electrolyte capacitance, $\mathrm{C}_{\text {interface) }}$ ZCPE2 (another constant phase, electrolyte capacitance, $C_{E}$ ) and a bulk resistance $R_{b}$ for the SPE (bulk electrolyte resistance, $R_{E}$ ) (see Figure $8 \mathrm{a}$ ). Two elements, $R_{b}$ and ZCPE1, are obtained in the high frequency region; in other words, both respond in the high frequencies, whereas the low frequency spike region is linked to ZCPE2. 
The EECs corresponding to Figure 7a,b are shown in Figure 8a. The ZCPE1 is the response of the double-layer capacitance formed at the interface region between the electrodes and the SPE [40]. It is possible to derive ZCPE's impedance as [41]:

$$
Z_{C P E}=\frac{1}{C \omega^{p}}\left[\cos \left(\frac{\pi p}{2}\right)-i \sin \left(\frac{\pi p}{2}\right)\right]
$$

where CPE is constant phase element, capacitance is represented by $\mathrm{C}$, the angular frequency is denoted by $\omega$ and $p$ is related to the departure of the plot from the vertical axis in complex impedance plots. It is worth mentioning that $\mathrm{CPE}$ is the acronym most commonly used instead of capacitor in the context of an EEC model. It is appealing to see that in such a system, the capacitor element in the circuit is replaced by CPE, where it is a capacitor system in an ideal or pure capacitor. Stated differently, this implies that the system is a semi-capacitor [40,42], which is the nature of a capacitor in the electrolyte/electrode system. This is not the case to recognize an ideal capacitor system in the existing experimental impedance spectra. For the case of expressing the real $(\mathrm{Zr})$, imaginary $(\mathrm{Zi})$ and complex impedance $\left(Z^{*}\right)$ values in the equivalent circuit, it can be formulated in a mathematical expression in the following way [41]:

$$
\begin{aligned}
& Z_{r}=\frac{R_{b} C_{1} \omega^{p 1} \cos \left(\frac{\pi p_{1}}{2}\right)+R_{b}}{2 R_{b} C_{1} \omega^{p} \cos \left(\frac{\pi p}{2}\right)+R_{b}^{2} C^{2} \omega^{2 p}+1}+\frac{\cos \left(\frac{\pi p_{2}}{2}\right)}{C_{2} \omega^{p 2}} \\
& Z_{i}=\frac{R_{b} C_{1} \omega^{p 1} \sin \left(\frac{\pi p_{1}}{2}\right)}{2 R_{b} C_{1} \omega^{p} \cos \left(\frac{\pi p}{2}\right)+R_{b}{ }^{2} C^{2} \omega^{2 p}+1}+\frac{\sin \left(\frac{\pi p_{2}}{2}\right)}{C_{2} \omega^{p 2}}
\end{aligned}
$$

where $R_{b}$ is the bulk resistance. Based on Equations (4) and (5), the experimental impedance plots are well simulated, as shown in Figure 7, and the EECs are presented in Figure 8. From the impedance spectra, it is obviously seen that the semicircle size dropped at the high frequency region as the concentration of salt increased $\left(20 \mathrm{wt} . \%\right.$ of $\left.\mathrm{NH}_{4} \mathrm{~F}\right)$. Figure $7 \mathrm{a}, \mathrm{b}$ exhibits a model comprising the incomplete semicircle, from which one can extract the value of $R_{b}$ that is parallel with the CPE element and series with another CPE relating to a low frequency tail, as shown schematically in Figure 8a. Predictably, the incomplete semicircle at $30 \mathrm{wt} . \%$ and $40 \mathrm{wt} . \%$ of $\mathrm{NH}_{4} \mathrm{~F}$ totally disappeared, as shown in Figure 7c,d. This indicates the possibility of the resistive behavior of SPEs and the CPE component in series, as shown schematically in Figure $8 \mathrm{~b}$. The equivalent circuit element parameters of the blend electrolytes are shown in Table 2. The logical explanation for this result, where the semicircle disappeared at the high frequency region in the spectra, is explained by the entire conductivity attributed to a huge ion migration [43]. In this case, the values of $Z_{r}$ and $Z_{i}$ are correlated to the EEC and can be expressed mathematically as follows:

$$
\begin{gathered}
Z_{r}=\frac{\cos \left(\frac{\pi p}{2}\right)}{C \omega^{p}}+R_{b} \\
Z_{i}=\frac{\sin \left(\frac{\pi p}{2}\right)}{C \omega^{p}}
\end{gathered}
$$

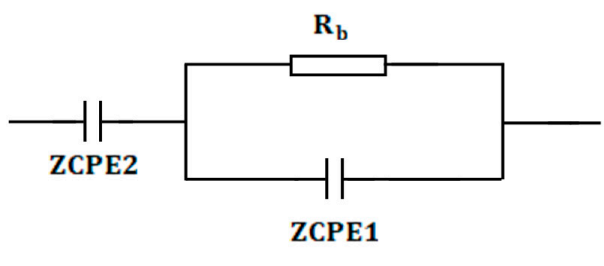

(a)

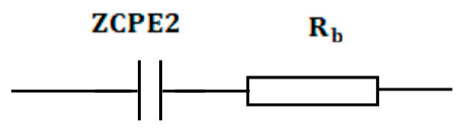

(b)

Figure 8. Schematic illustration of the EECs for (a) parallel combination of a resistor and capacitor in series with another capacitor and (b) series combination of a resistor and capacitor. The resistor is represented by the symbol $\square-$ and the capacitor is represented by $\longrightarrow$. 
Table 2. The parameters of the circuit elements of the blend electrolytes.

\begin{tabular}{ccccccc}
\hline Electrolytes & $\begin{array}{c}\boldsymbol{p}_{\mathbf{1}} \\
\text { (rad) }\end{array}$ & $\begin{array}{c}\boldsymbol{p}_{\mathbf{2}} \\
(\mathbf{r a d})\end{array}$ & $\begin{array}{c}\boldsymbol{k}_{\mathbf{1}} \\
\mathbf{( F}^{-\mathbf{1}} \mathbf{)}\end{array}$ & $\begin{array}{c}\boldsymbol{k}_{\mathbf{2}} \\
\mathbf{( F}^{-\mathbf{1}} \mathbf{)}\end{array}$ & $\begin{array}{c}\boldsymbol{C}_{\mathbf{1}} \\
\mathbf{( F )}\end{array}$ & $\begin{array}{c}\boldsymbol{C}_{\mathbf{2}} \\
\mathbf{( F )}\end{array}$ \\
\hline CMCF1 & 0.89 & 0.60 & $7.00 \times 10^{9}$ & $2.90 \times 10^{6}$ & $1.43 \times 10^{-10}$ & $3.45 \times 10^{-7}$ \\
CMCF2 & 0.56 & 0.77 & $4.00 \times 10^{6}$ & $2.55 \times 10^{6}$ & $2.50 \times 10^{-7}$ & $3.92 \times 10^{-7}$ \\
CMCF3 & - & 0.77 & - & $2.10 \times 10^{5}$ & - & $4.76 \times 10^{-6}$ \\
CMCF4 & - & 0.81 & - & $1.13 \times 10^{5}$ & - & $8.85 \times 10^{-6}$ \\
\hline
\end{tabular}

$k$ is the inverse of $C(k=1 / C)$.

\subsection{EDLC Characteristics}

\section{TNM and LSV Study}

To study total conductivity in SPBEs, TNM analysis was determined and the dominancy of ions to the total conductivity was verified. It was also proven that electrons partly contributed to the overall conductivity. Therefore, both electronic $\left(t_{e}\right)$ and ionic $\left(t_{i}\right)$ transference numbers can be obtained via:

$$
\begin{aligned}
t_{i} & =\frac{I_{i}-I_{S}}{I_{i}} \\
t_{i} & =1-t_{e}
\end{aligned}
$$

where $I_{i}$ is the current at the initial stage and $I_{S}$ is the current at the constant stage. Figure 9 displays the TNM plot for the highest conducting SPE. From the procedure, as the cell was disturbed by the working voltage of $0.2 \mathrm{~V}$, the value of $I_{i}$ was obtained at $15.7 \mathrm{~A}$. The high value of the current at the initial stage was assigned to both ions and electrons as charge-carrying species. As the procedure continued, a dramatic drop in the current was seen before reaching a constant value of $4.2 \mathrm{~A}$. Obviously, this decrease in the initial total current is ascribed to the depletion of the ionic species in the bulk electrolyte and became constant in the completely depleted state [43]. This phenomenon is explained on the basis of the ion-blocking effect at the stainless-steel electrodes. Kufian et al. [44] clarified this behavior and stated that, as polarization occurs in the cell, a constant current stage reaches its value and the cause of the remaining current flow is related to electrons alone. The values of $t_{e}$ and $t_{i}$ were determined to be 0.27 and 0.73 , respectively. This finding is of major importance, since it clarifies the main contribution of ions compared to electrons in the total conductivity. These data results are in good harmony with those reported for the carboxylmethylcellulose- $\mathrm{NH}_{4} \mathrm{~F}$ system by Ramlli and Isa [45]. Kyle et al. [46] recommended that the high value of the ionic transference number verifies to a large extent that the SPE behaves as an ionic conductor.

Among a number of characteristics of SPEs, electrochemical stability is critical, and from this one can decide the viability of SPEs in electrochemical devices. In this work, the potential window extended to $\sim 1 \mathrm{~V}$ [47]. Figure 10 exhibits the LSV for the relatively highly conducting SPE. Electrolytes used as electrode separators in EDLC devices will be subjected to a continuous process of rapid charge-discharge. During the charging process, a high voltage will be produced and the electrolyte film will breakdown. Thus, it is crucial to charge the EDLC to a potential value well below the breakdown voltage. Within the potential range from 0 to $1.7 \mathrm{~V}$, there was no significant current change as the potential swept. Despite the current rising beyond $1.7 \mathrm{~V}$, it was not considerable. As the potential exceeded $2.3 \mathrm{~V}$, the current rose significantly, indicating electrolyte decomposition at the surface of the inert electrodes [48]. Remarkably, it is realized that the CS:MC: $\mathrm{NH}_{4} \mathrm{~F}$ system is stable electrochemically within the specified potential range. Previously reported work [49] for an $\mathrm{NH}_{4} \mathrm{~F}$-based CS:dextran system found an electrochemical stability up to $1.7 \mathrm{~V}$. Therefore, the CS:MC: $\mathrm{NH}_{4} \mathrm{~F}$ system can be utilized in EDLC fabrication. 


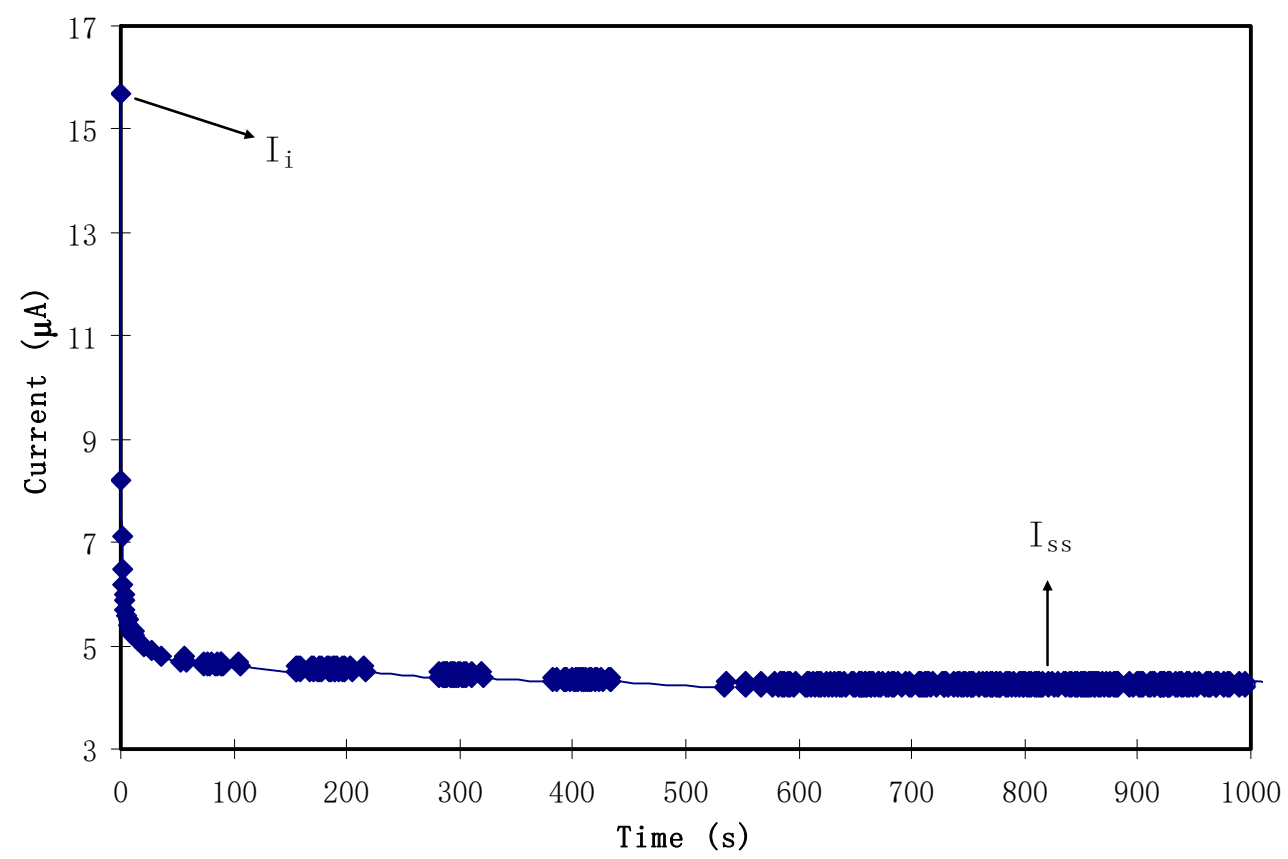

Figure 9. TNM plot for the highest conducting solid polymer electrolyte (SPE) with a polarization voltage of $0.2 \mathrm{~V}$.

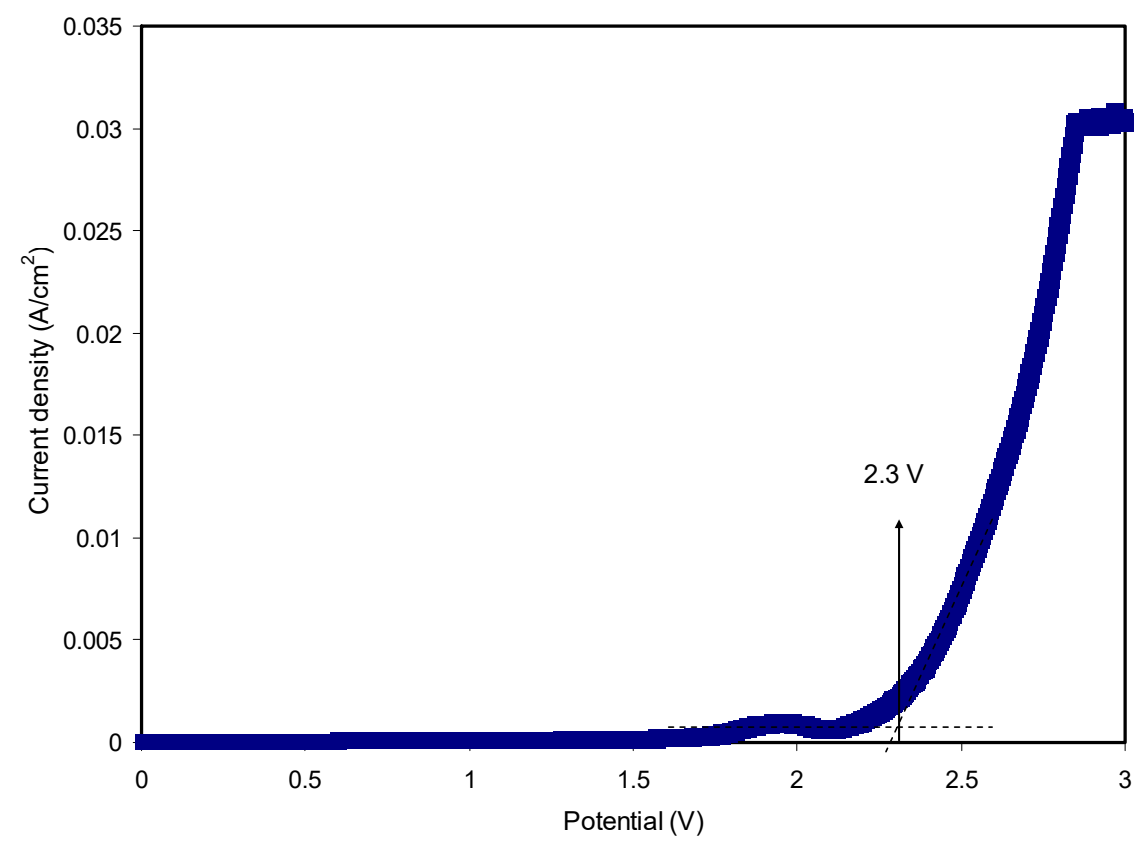

Figure 10. LSV plot for the highest conducting SPE with a scan rate of $50 \mathrm{mV} / \mathrm{s}$.

\subsection{EDLC}

To investigate capacitive behavior of an EDLC, it is the preliminary test to record cyclic voltammetry (CV). Figure 11a highlights the CV of the assembled EDLC at a sweep rate of $10 \mathrm{mV} / \mathrm{s}$. The schematic diagram for $\mathrm{CV}$ measurement is shown in Figure $11 \mathrm{~b}$ and the realist image of the prepared electrolyte after the LSV test is presented in Figure 11c. It is noticed that the shape of the CV is almost rectangular with the absence of any redox peaks. This is a good sign of the pure EDLC (completely capacitor) and there was no signature for the existence of pseudocapacitors in the energy storage system [50]. Therefore, the non-Faradaic charge storage comprises ion adsorption and accumulation at the interfacial region rather than an intercalation/deintercalation process. More clearly, both electrons and ions 
accumulate at the interface of electrodes and electrolyte, respectively. The charge accumulation in this region makes a double-layer charge regime in the form of potential energy [51]. Typically, an ideal capacitor manifests in a perfect rectangular shape of CV. The non-ideal rectangular shape of our CV might be caused by both internal resistance and electrode porosity [52]. To analyze the obtained results, it is calculable to find the specific capacitance $\left(C_{s p e}\right)$ of the assembled EDLC from the CV via the following equation:

$$
C_{s p e}=\int_{V_{i}}^{V_{f}} \frac{I(V) d V}{2 m v\left(V_{f}-V_{i}\right)}
$$

where $I(V) d V$ is the area of the CV which is determined using Origin 9.0 software through the integration function. The chosen $V_{i}$ and $V_{f}$ in the present work are $0 \mathrm{~V}$ and $0.9 \mathrm{~V}$, respectively, and $m$ and $v$ are the mass of used active material and sweep rate, respectively. The value of $C_{s p e}$ extracted from the $\mathrm{CV}$ was $58.3 \mathrm{~F} / \mathrm{g}$. This value is comparable to that obtained from the charge-discharge graph.

At a current density of $0.2 \mathrm{~mA} / \mathrm{cm}^{2}$, the rechargeability of the assembled EDLC is depicted in Figure 12a. From the figure, it can be seen that the plot is approximately linear in a triangular shape, which is a capacitive characteristic of the EDLC [53]. The results from the galvanostatic technique are in a high harmony with those from the capacitive $\mathrm{CV}$ analysis, confirming the capacitive behavior. It is straightforward to calculate specific capacitance $\left(C_{s}\right)$ from the slope $(s)$ of the charging and discharging curve using the following relationship:

$$
C_{s}=\frac{i}{s m}
$$

where $i$ is the applied current, which was $0.4 \mathrm{~mA}$ in the present work.

Figure $12 \mathrm{~b}$ presents $C_{s}$ for the complete 100 cycles. $C_{s}$ was $82.3 \mathrm{~F} / \mathrm{g}$ for the 1 st cycle. The relatively high value of $C_{S}$ in the initial few cycles was caused by the rapid development of the potential double layer due to electron and ion accumulation at the electrode and the electrolyte interfacial region. The value dropped to $78.4 \mathrm{~F} / \mathrm{g}$ in the 5 th cycle. This decline in specific capacitance value with increasing cycle number might be caused by ion association to form ion pairs or ion aggregation, which blocked the migration of free ions towards the carbon electrode [54]. Then, the value of $C_{s}$ stabilized from the 10 th cycle to the 100 th cycle with an average $C_{S}$ value of $64.1 \mathrm{~F} / \mathrm{g}$. This value was nearly the same as that obtained from the CV analysis. The study of the EDLC of various active materials and their corresponding specific capacitances are presented in Table 3.

Another two important parameters are efficiency $(\eta)$ and equivalent series resistance (ESR), which were determined for the assembled EDLC in 100 cycles. The $\eta$ value can be computed easily from the discharging $\left(t_{\text {dis }}\right)$ and charging $\left(t_{\text {cha }}\right)$ times, as shown in Figure 13a using the following equation:

$$
\eta=\frac{t_{d i s}}{t_{c h a}} \times 100
$$

From Figure 13a, one can see clearly that the $\eta$ in the 1st cycle was $43 \%$ and increased remarkably to $75 \%$ in the 5th cycle. The lower value of recorded $\eta$ in the initial cycle might owe to the longer duration of the charging process, where the ions and electrons built the charge double layer at the surface of the carbon electrodes/electrolyte. Almost the maximum value of $92 \%$ was reached in the 30th cycle, which then became constant at an average of $92.1 \%$ up to the 80 th cycle. At the steady state, charging time was almost the same as the discharging time, which is ideal for a typical capacitor. Interestingly, the value of $\eta$ decreased to $91.5 \%$ and $90.4 \%$ in the 90 th and 100 th cycles, respectively. The efficiency decline of the EDLC system resulted from the development of internal resistance. It is worth mentioning that $\eta$ was observed to be harmonized with $C_{s}$, when it lowered from $65.8 \mathrm{~F} / \mathrm{g}$ to 90.1 F/g in the 90th and 100th cycles, respectively. Shukur et al. [58] pointed out that a satisfactory EDLC must have $90-95 \% \eta$. It was also claimed that a relatively high value of efficiency reflects a compatible electrolyte-electrode contact. 


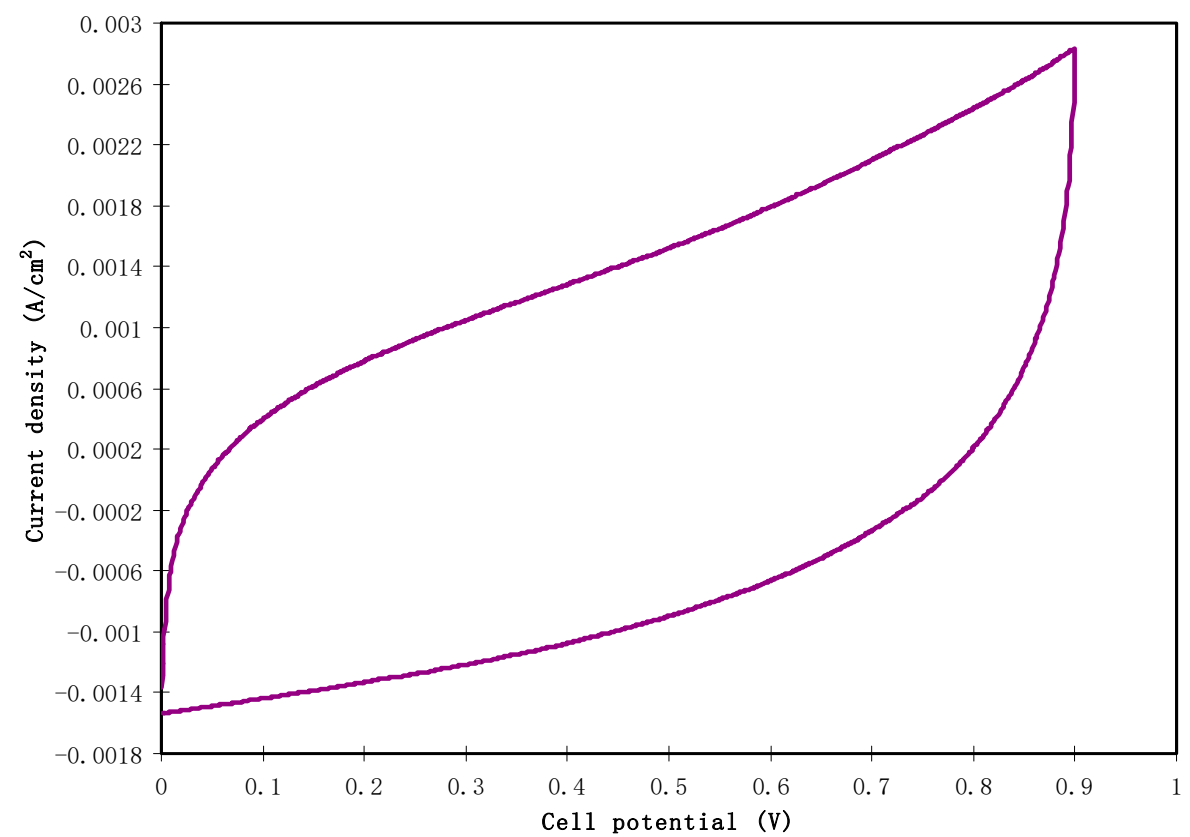

(a)

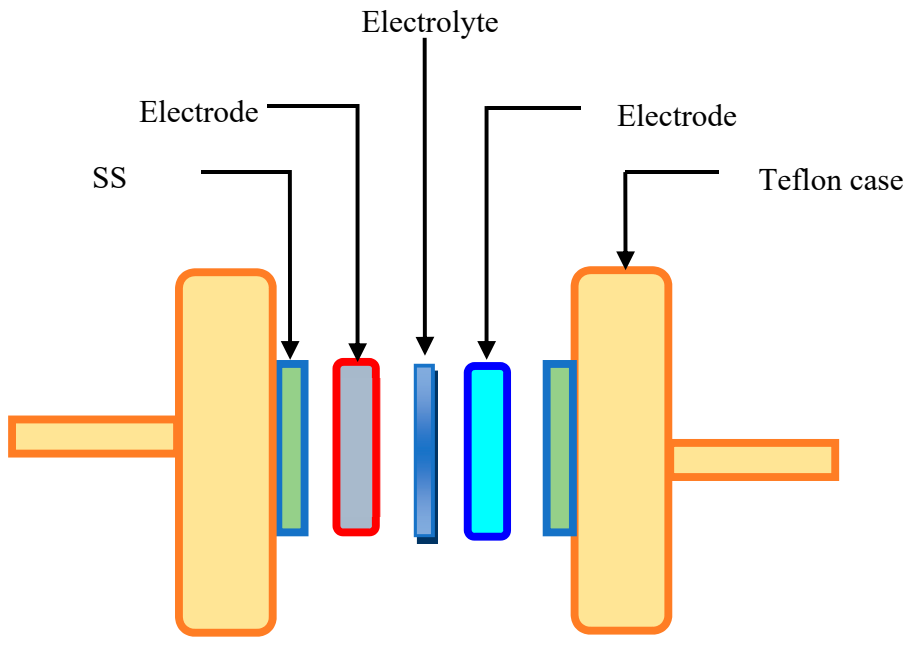

(b)

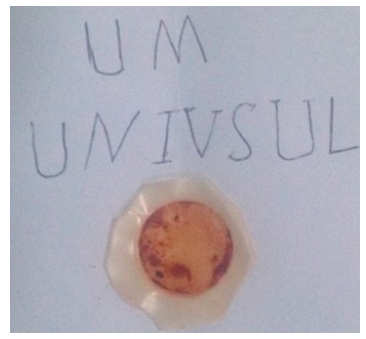

(c)

Figure 11. (a) CV measurement for the highest conducting SPE at $10 \mathrm{mV} / \mathrm{s}$ from 0 to $0.9 \mathrm{~V}$, (b) schematic diagram of the CV measurement unit for the fabricated electric double-layer capacitor (EDLC) cell, and (c) realist image of the highest conducting SPE when reaching the breakdown voltage. 


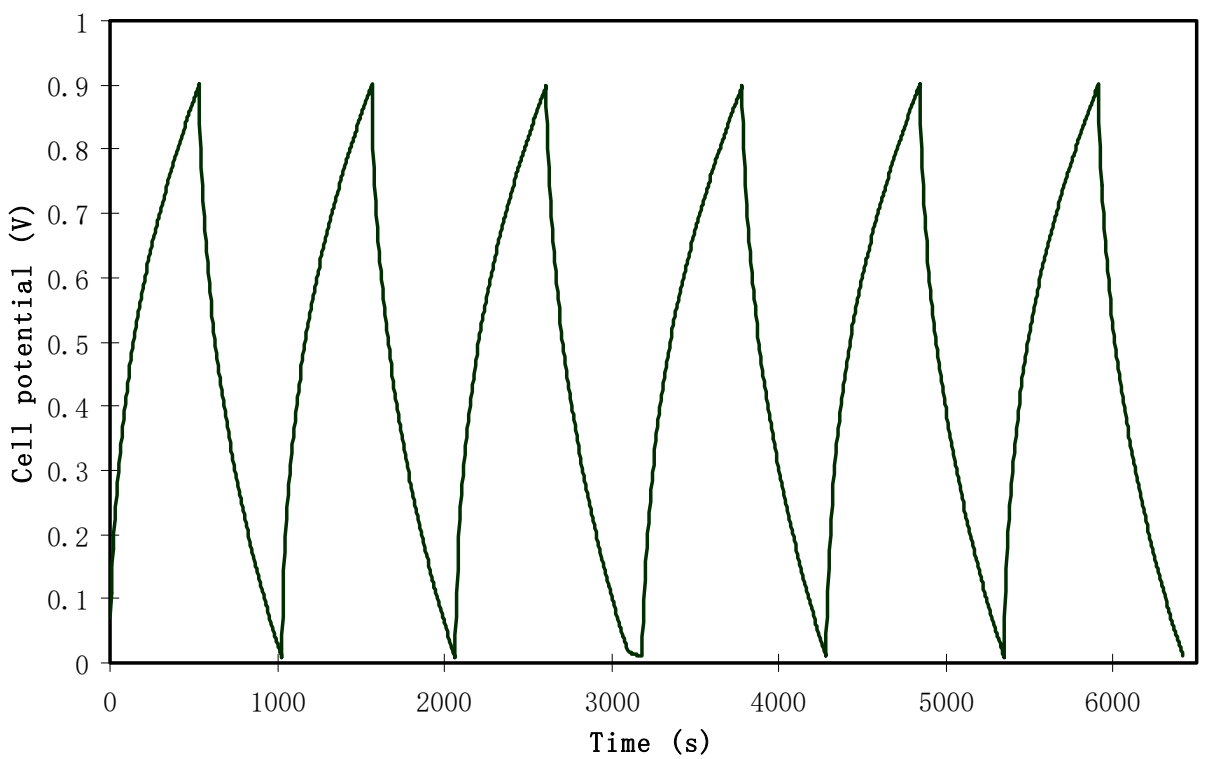

(a)

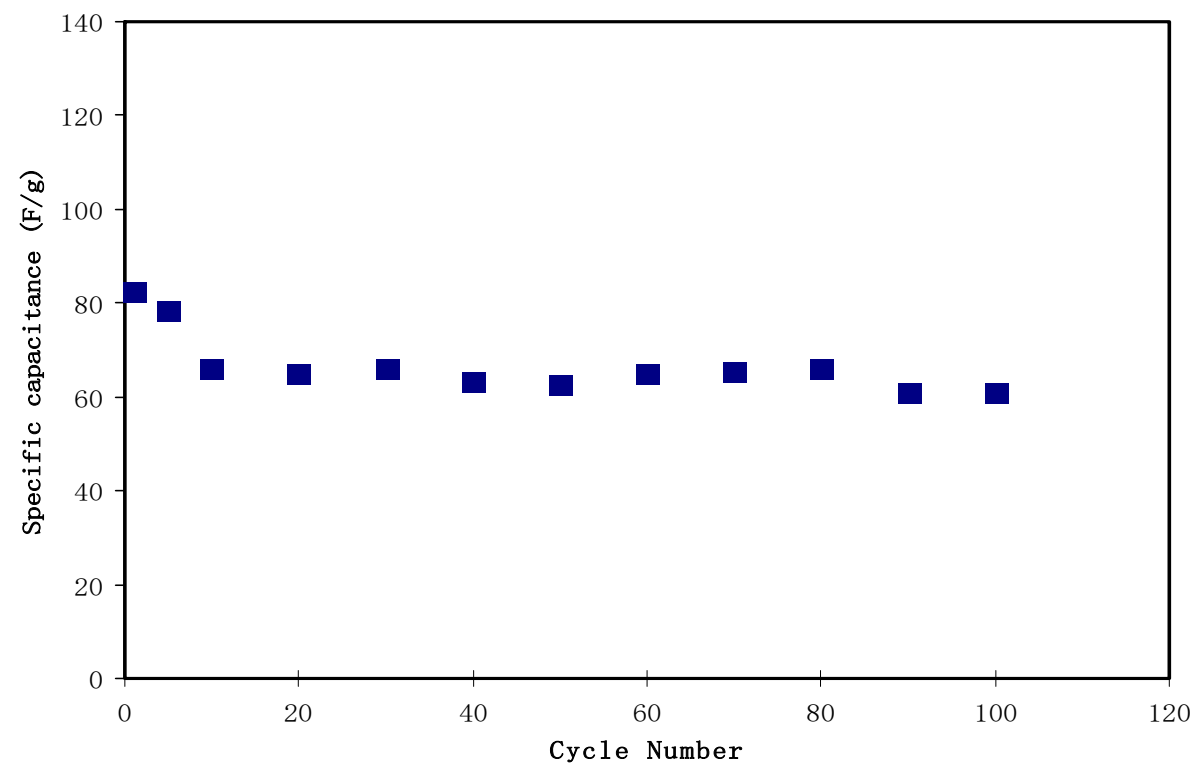

(b)

Figure 12. (a) Charge-discharge profile for the assembled EDLC at $0.2 \mathrm{~mA} / \mathrm{cm}^{2}$, (b) specific capacitance of the assembled EDLC for 100 cycles.

Table 3. EDLC studies with various active materials and their specific capacitances.

\begin{tabular}{|c|c|c|c|}
\hline System & Active Materials & $C_{s}(\mathrm{~F} / \mathrm{g})$ & Reference \\
\hline CS:poly(ethylene oxide) (PEO): $\mathrm{NH}_{4} \mathrm{SCN}$ & Activated carbon & 3.8 & [55] \\
\hline Poly(vinyl alcohol)(PVA):dextran: $\mathrm{NH}_{4} \mathrm{I}$ & Activated carbon & 4.2 & [56] \\
\hline CS: $\mathrm{MC}: \mathrm{NH}_{4} \mathrm{I}$ & Activated carbon & 6.9 & [8] \\
\hline CS:Dextran: $\mathrm{NH}_{4} \mathrm{I}$ & Activated carbon & 19.1 & [10] \\
\hline $\begin{array}{c}\text { Hydroxylethyl cellulose }+\mathrm{MgTf}_{2}+\text { EMIMT } \\
+ \text { silica nanoparticles }\end{array}$ & Activated carbon & 25.1 & [1] \\
\hline $\mathrm{PVA}+\mathrm{CH}_{3} \mathrm{COONH}_{4}+\mathrm{BmImCl}$ & Activated carbon & 31.3 & [3] \\
\hline $\mathrm{MC}+\mathrm{NH}_{4} \mathrm{NO}_{3}+\mathrm{PEG}$ & PEG/Activated carbon & 38 & [50] \\
\hline PVA/polystyrene & Carbon & 40 & [57] \\
\hline Cellulose $+\mathrm{Na}_{2} \mathrm{SO}_{4}$ & Cellulose nanofiber + graphite & 43 & [21] \\
\hline $\mathrm{CS} / \mathrm{MC}+\mathrm{NH}_{4} \mathrm{~F}$ & Activated carbon & 64.1 & This work \\
\hline
\end{tabular}




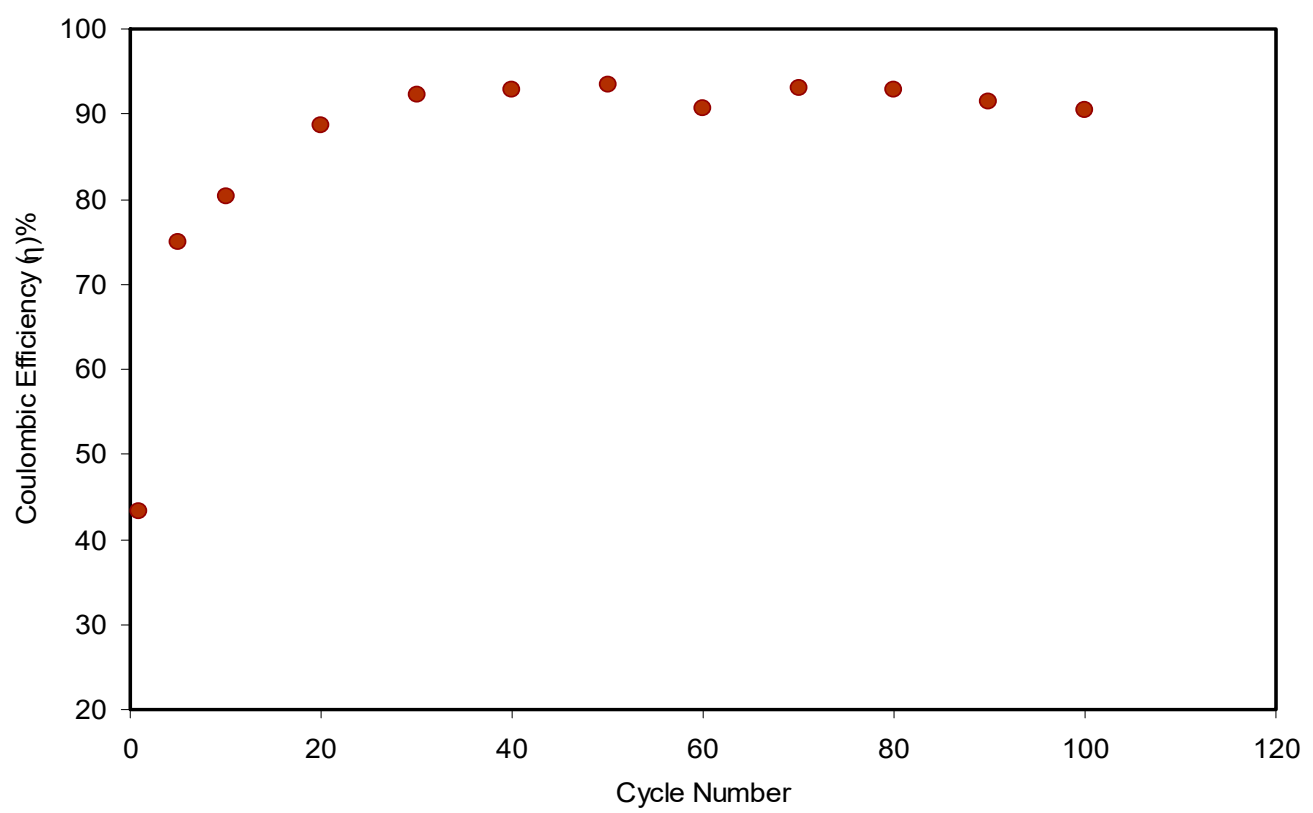

(a)

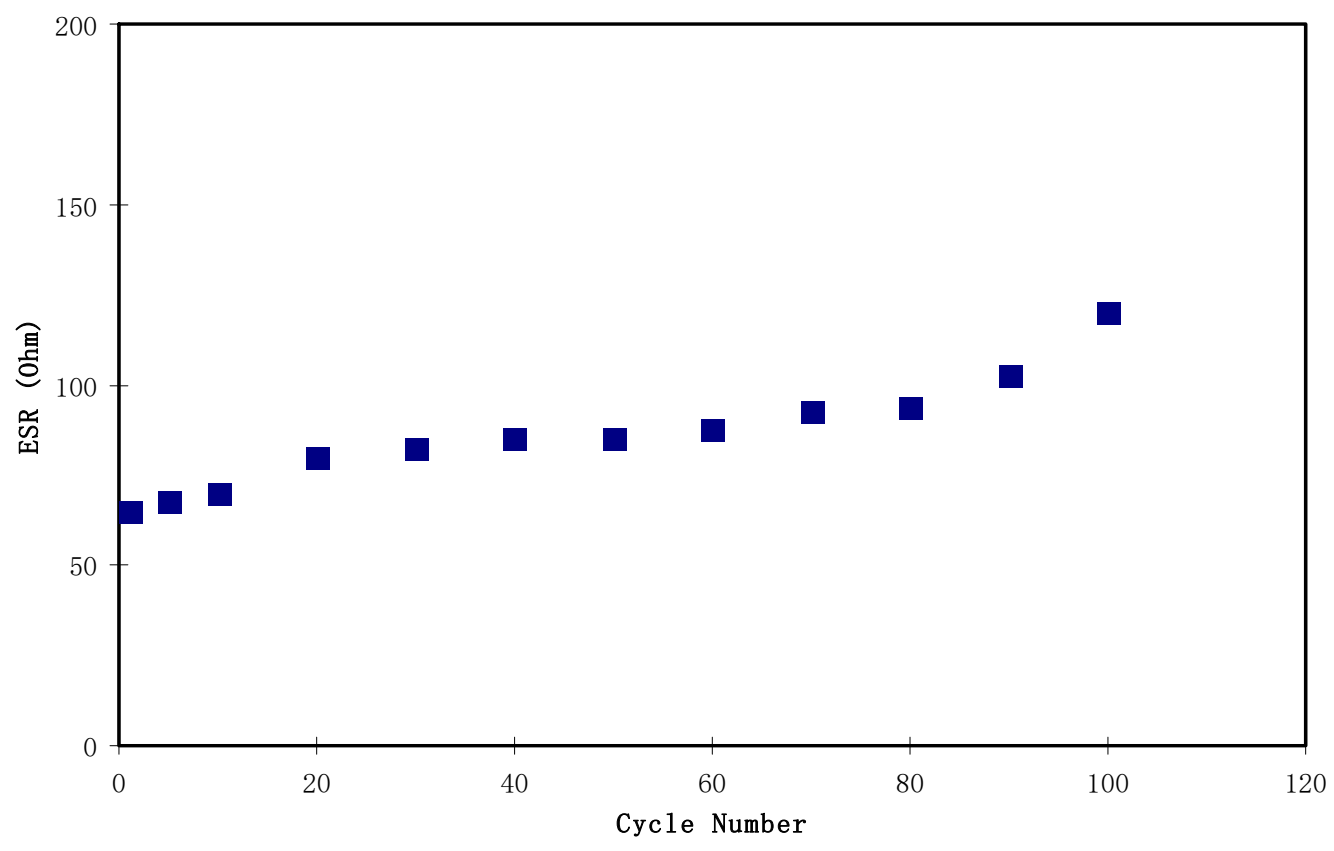

(b)

Figure 13. (a) Efficiency of the assembled EDLC for 100 cycles and (b) internal resistance of the assembled EDLC for 100 cycles.

Figure 12 a showed that the drop voltage $\left(V_{\text {drop }}\right)$ in the charge-discharge profile starts insignificantly prior to the discharging process starting in the assembled EDLC system. This $V_{\text {drop }}$ of the assembled EDLC in the present study was quantized, ranging from 0.026 to $0.048 \mathrm{~V}$. This drop in potential might be related to the development of internal resistance in the bulk electrolyte, which is called equivalent series resistance $(E S R)$ and can be calculated from the following relationship:

$$
E S R=\frac{V_{d r o p}}{i}
$$


The equivalent series resistance (ESR) of the EDLC for the complete 100 cycles is exhibited in Figure 13b. From the figure, the value of ESR in the 1 st cycle was $65 \Omega$ and increased to $75 \Omega$ in the 10th cycle. One of the interesting observations is an almost constant value of ESR from the 20th to the 80th cycle, with an average value of $86.6 \Omega$. Furthermore, the ESR value increased to $102 \Omega$ and $120 \Omega$ as the cycle number was increased to 90 and 100, respectively. A harmonized trend is seen in the pattern of $C_{s}$ and $\eta$, where it is almost constant from the 20th cycle to the 80th cycle and starts to drop at the 90th cycle. Herein, three main factors are discussed that caused this increase in the internal resistance of the EDLC. Firstly, ion aggregation was formed from a rapid charge-discharge process. Secondly, the electrode-electrolyte gap resulted in an increase in the internal resistance. Thirdly, there was a technical issue caused by the fabrication of carbon electrodes on the aluminum current collector [59].

The crucial parameters in the investigation of an EDLC are energy $\left(E_{d e n}\right)$ and power $\left(P_{d e n}\right)$ density. The energy density $(\mathrm{Wh} / \mathrm{kg}$ ) shows how much energy can be stored by an EDLC, whereas power density $(\mathrm{W} / \mathrm{kg})$ is a measure of the energy or power that can be delivered by an EDLC [60]. Simply, both $E_{d e n}$ and $P_{d e n}$ can be obtained from the equations shown below:

$$
\begin{gathered}
E_{d e n}=\frac{C_{s} V}{2} \\
P_{\text {des }}=\frac{V^{2}}{4 m(E S R)}
\end{gathered}
$$

Figure $14 \mathrm{a}, \mathrm{b}$ presents the energy density and power density of the fabricated EDLC for 100 cycles, respectively. The applied voltage $(\mathrm{V})$ on the assembled EDLC in the present work was $0.9 \mathrm{~V}$ and the magnitudes of both $E_{d e n}$ and $P_{d e n}$ in the 1 st cycle were $9.3 \mathrm{Wh} / \mathrm{kg}$ and $1282 \mathrm{~W} / \mathrm{kg}$, respectively. These magnitudes dropped to $7.3 \mathrm{Wh} / \mathrm{kg}$ and $1041 \mathrm{~W} / \mathrm{kg}$ at the 20th cycle for the energy density and power density, respectively. From the data analysis, it was recorded that the energy density magnitude was almost constant at an average of $7.3 \mathrm{Wh} / \mathrm{kg}$ and the power density magnitude remained nearly constant at $964 \mathrm{~W} / \mathrm{kg}$ from the 20th cycle to the 80th cycle. The key observation is that the magnitudes of energy and power density exhibited a significant lowering in the 90th and 100th cycles.

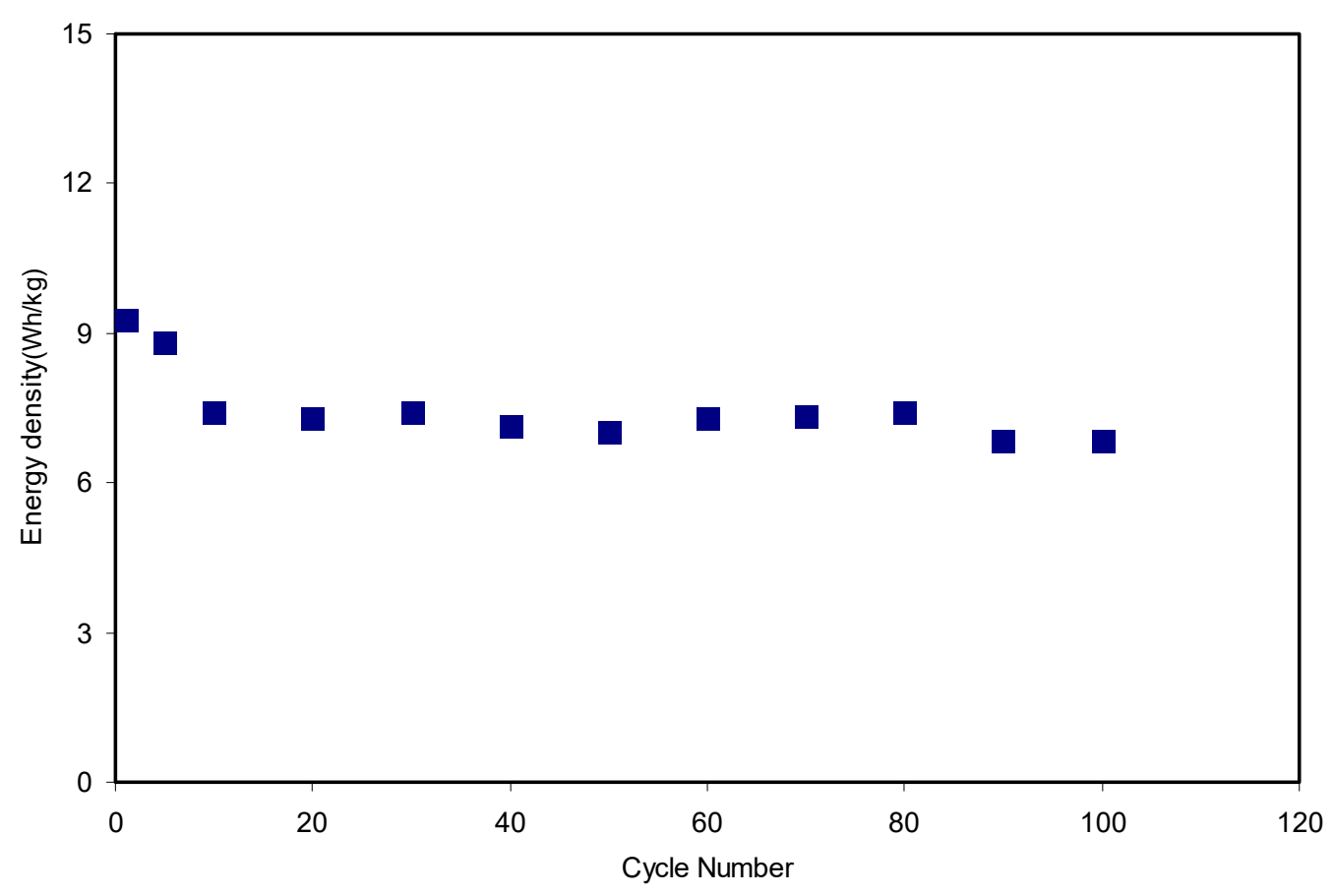

(a)

Figure 14. Cont. 


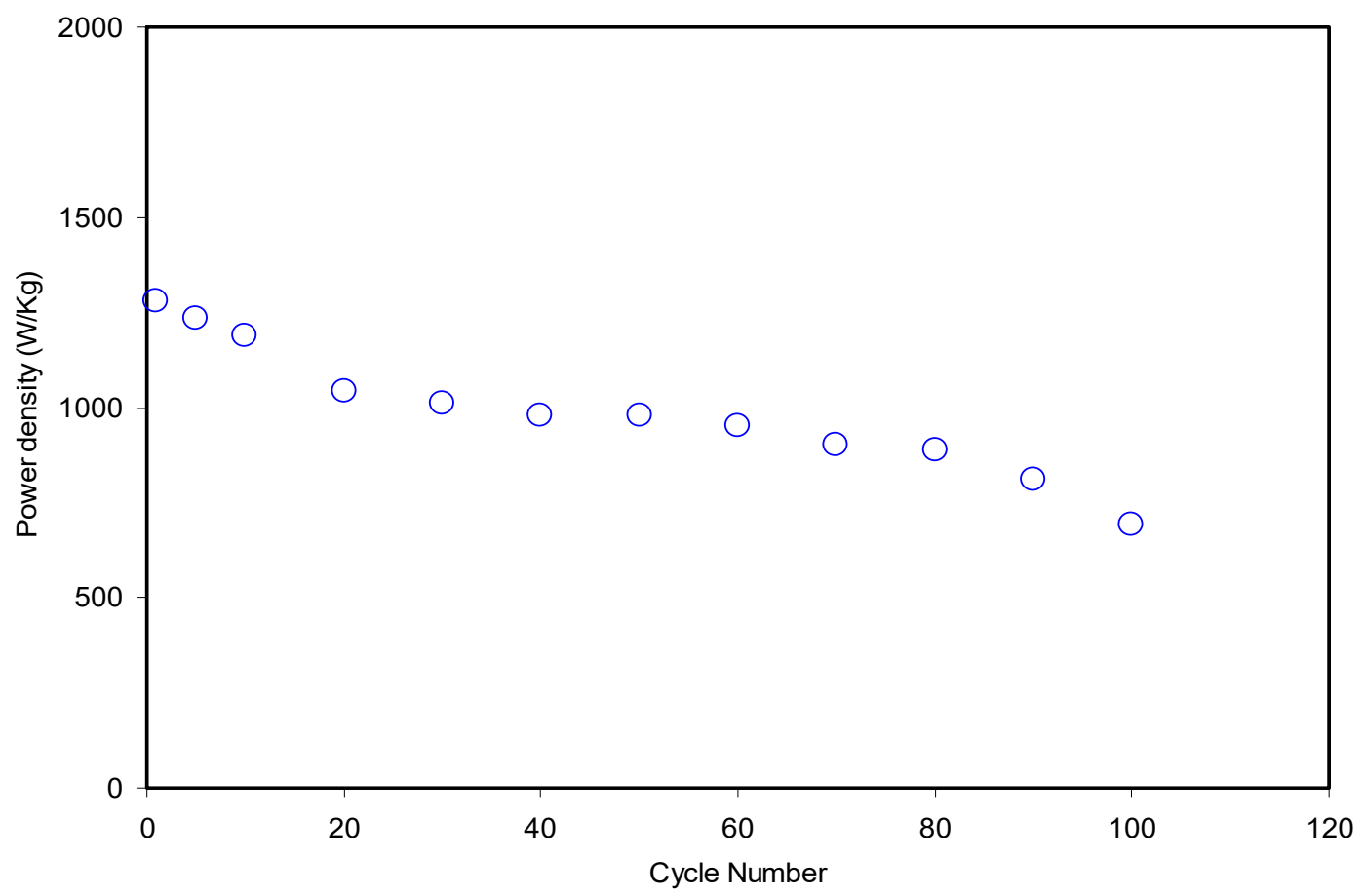

(b)

Figure 14. (a) Energy density of the assembled EDLC for 100 cycles and (b) power density of the assembled EDLC for 100 cycles.

These patterns harmonized with the patterns of $C_{s}, \eta$ and ESR. From an earlier study [18], the EDLC of the CS:dextran: $\mathrm{NH}_{4} \mathrm{~F}$ electrolyte as the electrode separator reached magnitudes of $1.4 \mathrm{Wh} / \mathrm{kg}$ and $428 \mathrm{~W} / \mathrm{kg}$ for $E_{d e n}$ and $P_{d e n}$, respectively. The higher magnitudes of both the energy and power density recorded for the current work might be due to the lower extent of crystallinity of MC compared to dextran. In other words, the high ion mobility governs these crucial parameters. Furthermore, even from other studies, the degree of the crystallinity of dextran was reported to be 35.92 [61], while for $\mathrm{MC}$, it was 32.89 [62]. It emphasized to a large extent that the conduction of ions is favorable in the amorphous region [63]. Ultimately, it is realized that the ion conduction in the CS:MC system is greater than in the CS:dextran host towards the electrode surface. Therefore, the more ions that diffuse and migrate towards the electrode surface, the larger the development of charge double layers, which in turn results in higher energy storage, and better performance of the EDLC. A consistent value of energy density during the ion transport towards the carbon electrodes confirms that ions in the CS:MC: $\mathrm{NH}_{4} \mathrm{~F}$ electrolyte experience the same energy barrier [64]. Generally, the EDLC performance decline based on $C_{s}, \eta, E_{d e n}$ and $P_{d e n}$ magnitudes is due to electrolyte depletion. It is worth mentioning that the rapid charge-discharge process causes free ions to recombine back to from aggregated ions, and consequently electrolyte depletion takes place. Eventually, the depletion of electrolyte phenomenon lowers the potential energy growth at the surface of the carbon electrodes [65-70].

\section{Conclusions}

In this work, a solid polymer blend electrolyte (SPBE), based on CS and MS incorporated with different amounts of $\mathrm{NH}_{4} \mathrm{~F}$, was prepared. The possibility of employing the prepared SPBE in EDLC fabrication was investigated and the performance of the device was analyzed. The FTIR spectra revealed that there was a strong interaction between $\mathrm{CS}, \mathrm{MS}$ and even $\mathrm{NH}_{4} \mathrm{~F}$ as a dopant. Both the peak shifting and intensity reduction of the XRD pattern were a good indication of the interaction between the components of the system. The structural analysis of the system confirmed the prevalence of an amorphous region. From EIS, the improvement of conductivity with increasing salt concentration 
was highlighted due to a rise in the number of mobile charge carriers. The charge carrying in total conduction mainly depended on ions, whereas electrons were a less common contributor, as $t_{e}$ and $t_{i}$ were determined to be 0.27 and 0.73 , respectively. The rectangular shape of the $C V$ revealed the presence of pure EDLC with capacitive behavior and recorded a high specific capacitance of $64.1 \mathrm{~F} / \mathrm{g}$. The high efficiency (above 90\%) proved a good electrode-electrolyte contact. The suitability of the EDLC system was justified via energy and power density analysis. The relatively low value $(86.6 \Omega)$ of equivalent series resistance (ESR) over 80 cycles supported the good performance of the fabricated EDLC. Overall, the high conduction and electrochemical stability are behind the obtained relatively high energy and power density of $7.3 \mathrm{Wh} / \mathrm{kg}$ and $964 \mathrm{~W} / \mathrm{kg}$, respectively. Finally, it was concluded that the high conduction, electrochemical stability, low equivalent series resistance and amorphous nature played crucial roles in the good performance of the EDLC cell.

Author Contributions: Conceptualization, S.B.A., M.M.N., S.R.S., M.F.Z.K., S.J.M. and S.A.-Z.; Formal analysis, S.B.A. and M.H.H.; Investigation, S.B.A. and M.H.H.; Methodology, S.B.A. and M.H.H.; Project administration, S.B.A. and M.M.N.; Validation, S.S., R.T.A., M.A.B. and S.A.-Z.; Visualization, S.J.M.; Writing-original draft, S.B.A. and M.H.H.; Writing-review and editing, M.M.N., S.S., R.T.A., S.R.S., M.A.B., M.F.Z.K. and S.A.-Z. All authors have read and agreed to the published version of the manuscript.

Funding: The authors gratefully acknowledge the financial support for this study from the Ministry of Higher Education and Scientific Research-Kurdish National Research Council (KNRC), Kurdistan Regional Government/Iraq and the Prince Sultan University.

Acknowledgments: The authors gratefully acknowledge the financial support for this study from Ministry of Higher Education and Scientific Research, Kurdish National Research Council (KNRC), Kurdistan Regional Government/Iraq. The financial support from the University of Sulaimani and Komar Research Center (KRC), Komar University of Science and Technology are greatly appreciated.

Conflicts of Interest: The authors declare no conflict of interest.

\section{References}

1. Chong, M.Y.; Numan, A.; Liew, C.W.; Ng, H.; Ramesh, K.; Ramesh, S. Enhancing the performance of green solid-state electric double-layer capacitor incorporated with fumed silica nanoparticles. J. Phys. Chem. Solids 2018, 117, 194-203. [CrossRef]

2. Ramaswamy, M.; Malayandi, T.; Subramanian, S.; Srinivasalu, J.; Rangaswamy, M.; Soundararajan, V. Development and Study of Solid Polymer Electrolyte Based on Polyvinyl Alcohol: Mg (ClO 4) 2. Polym. Technol. Eng. 2017, 56, 992-1002. [CrossRef]

3. Liew, C.W.; Ramesh, S.; Arof, A.K. Good prospect of ionic liquid-based poly (vinyl alcohol) polymer electrolytes for supercapacitors with excellent electrical, electrochemical and thermal properties. Int. J. Hydrogen Energy 2014, 39, 2953-2963. [CrossRef]

4. Shujahadeen, B.A.; Brza, M.A.; Salah, R.S.; Hamsan, M.H.; Kadir, M.F.Z. Ion association as a main shortcoming in polymer blend electrolytes based on CS: PS incorporated with various amounts of ammonium tetrafluoroborate. J. Mater. Res. Technol. 2020, 9, 5410-5421. [CrossRef]

5. Aziz, N.A.N.; Idris, N.K.; Isa, M.I.N.M. Solid Polymer Electrolytes Based on Methylcellulose: FT-IR and Ionic Conductivity Studies. Int. J. Polym. Anal. Charact. 2010, 15, 319-327. [CrossRef]

6. Saadiah, M.; Zhang, D.; Nagao, Y.; Muzakir, S.; Samsudin, A. Reducing crystallinity on thin film-based CMC/PVA hybrid polymer for application as a host in polymer electrolytes. J. Non-Cryst. Solids 2019, 511, 201-211. [CrossRef]

7. Taghizadeh, M.T.; Seifi-Aghjekohal, P.; Taghizadeh, M.T. Sonocatalytic degradation of 2-hydroxyethyl cellulose in the presence of some nanoparticles. Ultrason. Sonochem. 2015, 26, 265-272. [CrossRef]

8. Aziz, S.B.; Hamsan, M.; Brza, M.; Kadir, M.; Muzakir, S.; Abdulwahid, R.T. Effect of glycerol on EDLC characteristics of chitosan: Methylcellulose polymer blend electrolytes. J. Mater. Res. Technol. 2020, 9, 8355-8366. [CrossRef]

9. Mathew, C.M.; Karthika, B.; Ulaganathan, M.; Rajendran, S. Electrochemical analysis on poly (ethyl methacrylate)-based electrolyte membranes. Bull. Mater. Sci. 2015, 38, 151-156. [CrossRef] 
10. Aziz, S.B.; Hamsan, M.H.; Nofal, M.M.; Karim, W.O.; Brevik, I.; Brza, M.; Abdilwahid, R.T.; Al-Zangana, S.; Kadir, M.F.Z. Structural, Impedance and Electrochemical Characteristics of Electrical Double Layer Capacitor Devices Based on Chitosan: Dextran Biopolymer Blend Electrolytes. Polymers 2020, 12, 1411. [CrossRef]

11. Aziz, S.B.; Brza, M.A.; Hamsan, H.M.; Kadir, M.F.Z.; Abdulwahid, R.T. Electrochemical characteristics of solid-state double-layer capacitor constructed from proton conducting chitosan-based polymer blend electrolytes. Polym. Bull. 2020. [CrossRef]

12. Aziz, S.B.; Hamsan, M.H.; Abdullah, R.M.; Abdulwahid, R.T.; Brza, M.A.; Marif, A.S.; Kadir, M.F.Z. Protonic EDLC cell based on chitosan (CS): Methylcellulose (MC) solid polymer blend electrolytes. Ionics 2020, 26, 1829-1840. [CrossRef]

13. Hwang, H.; Park, S.Y.; Kim, J.K.; Kim, Y.M.; Moon, H.C. Star-Shaped Block Copolymers: Effective Polymer Gelators of High-Performance Gel Electrolytes for Electrochemical Devices. ACS Appl. Mater. Interfaces 2019, 11, 4399-4407. [CrossRef]

14. Singh, P.; Bharati, D.C.; Gupta, P.N.; Saroj, A. Vibrational, thermal and ion transport properties of PVA-PVP-PEG-MeSO4Na based polymer blend electrolyte films. J. Non-Cryst. Solids 2018, 494, 21-30. [CrossRef]

15. Prajapati, G.; Roshan, R.; Gupta, P.N. Effect of plasticizer on ionic transport and dielectric properties of PVA-H3PO4 proton conducting polymeric electrolytes. J. Phys. Chem. Solids 2010, 71, 1717-1723. [CrossRef]

16. Misenan, M.S.M.; Isa, M.I.N.M.; Khiar, A.S.A. Electrical and structural studies of polymer electrolyte based on chitosan/methyl cellulose blend doped with BMIMTFSI. Mater. Res. Express 2018, 5, 055304. [CrossRef]

17. Radha, K.P.; Selvasekarapandian, S.; Karthikeyan, S.; Hema, M.; Sanjeeviraja, C. Synthesis and impedance analysis of proton-conducting polymer electrolyte PVA: NH4F. Ionics 2013, 19, 1437-1447. [CrossRef]

18. Aziz, S.B.; Hamsan, M.H.; Karim, W.O.; Kadir, M.; Brza, M.A.; Abdullah, O.G. High Proton Conducting Polymer Blend Electrolytes Based on Chitosan:Dextran with Constant Specific Capacitance and Energy Density. Biomolecules 2019, 9, 267. [CrossRef] [PubMed]

19. Lee, D.-Y.; Sohn, J.I.; Ahn, H.-J. High-surface-area tofu based activated porous carbon for electrical double-layer capacitors. J. Ind. Eng. Chem. 2017, 52, 121-127. [CrossRef]

20. Guo, J.; Jiang, J.; Yang, B. Low-voltage electric-double-layer MoS2 transistor gated via water solution. Solid-State Electron. 2018, 150, 8-15. [CrossRef]

21. Andres, B.; Dahlström, C.; Blomquist, N.; Norgren, M.; Olin, H. Cellulose binders for electric double-layer capacitor electrodes: The influence of cellulose quality on electrical properties. Mater. Des. 2018, 141, 342-349. [CrossRef]

22. Yang, I.; Kim, S.-G.; Kwon, S.H.; Lee, J.H.; Kim, M.-S.; Jung, J.C. Pore size-controlled carbon aerogels for EDLC electrodes in organic electrolytes. Curr. Appl. Phys. 2016, 16, 665-672. [CrossRef]

23. Tran, C.; Kalra, V. Fabrication of porous carbon nanofibers with adjustable pore sizes as electrodes for supercapacitors. J. Power Sour. 2013, 235, 289-296. [CrossRef]

24. Zhao, X.-Y. Key Laboratory of Coal Processing and Efficient Utilization (Ministry of Education), China University of Mining \& Technology, Xuzhou 221116, Jiangsu, China Preparation and Characterization of Activated Carbons from Oxygen-rich Lignite for Electric Double-layer Capacitor. Int. J. Electrochem. Sci. 2018, 13, 2800-2816. [CrossRef]

25. Xu, M.; Li, D.; Yan, Y.; Guo, T.; Pang, H.; Xue, H. Porous high specific surface area-activated carbon with co-doping N, S and P for high-performance supercapacitors. RSC Adv. 2017, 7, 43780-43788. [CrossRef]

26. Nurhaziqah, A.M.S.; Afiqah, I.Q.; Aziz, M.F.H.A.; Aziz, N.A.N.; Hasiah, S. Optical, Structural and Electrical Studies of Biopolymer Electrolytes Based on Methylcellulose Doped with Ca (NO3)2. IOP Conf. Series Mater. Sci. Eng. 2018, 440, 012034. [CrossRef]

27. Aziz, S.B.; Hamsan, M.H.; Abdullah, R.M.; Kadir, M.F.Z. A Promising Polymer Blend Electrolytes Based on Chitosan: Methyl Cellulose for EDLC Application with High Specific Capacitance and Energy Density. Molecules 2019, 24, 2503. [CrossRef]

28. Aziz, S.B.; Abidin, Z.H.Z.; Kadir, M.F.Z. Innovative method to avoid the reduction of silver ions to silver nanoparticles $\left(\mathrm{Ag}^{+} \rightarrow \mathrm{Ag}^{\mathrm{o}}\right)$ in silver ion conducting based polymer electrolytes. Phys. Scr. 2015, 90, 35808. [CrossRef]

29. He, Y.; Zhu, B.; Inoue, Y. Hydrogen bonds in polymer blends. Prog. Polym. Sci. 2004, 29, 1021-1051. [CrossRef] 
30. Lu, G.; Kong, L.; Sheng, B.; Wang, X.; Gong, Y.; Zhang, X. Degradation of covalently cross-linked carboxymethyl chitosan and its potential application for peripheral nerve regeneration. Eur. Polym. J. 2007, 43, 3807-3818. [CrossRef]

31. Aziz, S.B.; Marif, R.B.; Brza, M.; Hassan, A.N.; Ahmad, H.A.; Faidhalla, Y.A.; Kadir, M. Structural, thermal, morphological, and optical properties of PEO filled with biosynthesized Ag nanoparticles: New insights to band gap study. Results Phys. 2019, 13, 102220. [CrossRef]

32. Wen, S.; Richardson, T.; Ghantous, D.; Striebel, K.; Ross, P.; Cairns, E.J. FTIR characterization of PEO + LiN (CF3SO2)2 electrolytes. J. Electroanal. Chem. 1996, 408, 113-118. [CrossRef]

33. Aziz, S.B.; Abidin, Z.H.Z. Electrical Conduction Mechanism in Solid Polymer Electrolytes: New Concepts to Arrhenius Equation. J. Soft Matter 2013, 1-8. [CrossRef]

34. Sahli, N.B.; Ali, A.M.M. Effect of lithium triflate salt concentration in methyl cellulose-based solid polymer electrolytes. In Proceedings of the 2012 IEEE Colloquium on Humanities, Science and Engineering (CHUSER), Kota Kinabalu, Malaysia, 3-4 December 2012; pp. 739-742. [CrossRef]

35. Kamarudin, K.H.; Isa, M.I.N. Structural and DC Ionic conductivity studies of carboxy methylcellulose doped with ammonium nitrate as solid polymer electrolytes. Int. J. Phys. Sci. 2013, 8, 1581-1587. [CrossRef]

36. Samsudin, A.S.; Kuan, E.C.H.; Isa, M.I.N.M. Investigation of the Potential of Proton-Conducting Biopolymer Electrolytes Based Methyl Cellulose-Glycolic Acid. Int. J. Polym. Anal. Charact. 2011, 16, 477-485. [CrossRef]

37. Aziz, S.B.; Karim, W.O.; Qadir, K.; Zafar, Q. Proton Ion Conducting Solid Polymer Electrolytes Based on Chitosan Incorporated with Various Amounts of Barium Titanate (BaTiO3). Int. J. Electrochem. Sci. 2018, 13, 6112-6125. [CrossRef]

38. Pradhan, D.K.; Choudhary, R.N.; Samantaray, B.K.; Karan, N.K.; Katiyar, R.S. Effect of Plasticizer on Structural and Electrical Properties of Polymer Nanocompsoite Electrolytes. Int. J. Electrochem. Sci. 2007, 2, 861-871.

39. Mohapatra, S.R.; Thakur, A.K.; Choudhary, R. Effect of nanoscopic confinement on improvement in ion conduction and stability properties of an intercalated polymer nanocomposite electrolyte for energy storage applications. J. Power Sour. 2009, 191, 601-613. [CrossRef]

40. Aziz, S.B.; Abdullah, R.M.; Kadir, M.; Ahmed, H.M. Non suitability of silver ion conducting polymer electrolytes based on chitosan mediated by barium titanate (BaTiO3) for electrochemical device applications. Electrochim. Acta 2019, 296, 494-507. [CrossRef]

41. Aziz, S.B.; Woo, T.J.; Kadir, M.F.; Ahmed, H.M.; Ahmed, H.M. A conceptual review on polymer electrolytes and ion transport models. J. Sci. Adv. Mater. Devices 2018, 3, 1-17. [CrossRef]

42. Aziz, S.B.; Hamsan, M.; Brza, M.; Kadir, M.; Abdulwahid, R.T.; Ghareeb, H.O.; Woo, H. Fabrication of energy storage EDLC device based on CS: PEO polymer blend electrolytes with high $\mathrm{Li}+$ ion transference number. Results Phys. 2019, 15, 102584. [CrossRef]

43. Sekhon, S.S.; Agnihotry, S.A. Solid State Ionics: Science and Technology; Chowdari, B.V.R., Lal, K., Agnihotry, S.A., Khare, N., Sekhon, S.S., Srivastava, P.C., Chandra, S., Eds.; World Scientific: Singapore, 1998; p. 527.

44. Kufian, M.Z.; Aziz, M.F.; Shukur, M.; Rahim, A.; Ariffin, N.; Shuhaimi, N.; Majid, S.; Yahya, R.; Arof, A.K. PMMA-LiBOB gel electrolyte for application in lithium ion batteries. Solid State Ionics 2012, 208, 36-42. [CrossRef]

45. Ramlli, M.A.; Isa, M.I.N.M. Structural and Ionic Transport Properties of Protonic Conducting Solid Biopolymer Electrolytes Based on Carboxymethyl Cellulose Doped with Ammonium Fluoride. J. Phys. Chem. B 2016, 120, 11567-11573. [CrossRef] [PubMed]

46. Diederichsen, K.M.; McShane, E.J.; McCloskey, B.D. Promising Routes to a High Li+ Transference Number Electrolyte for Lithium Ion Batteries. ACS Energy Lett. 2017, 2, 2563-2575. [CrossRef]

47. Pratap, R.; Singh, B.; Chandra, S. Polymeric rechargeable solid-state proton battery. J. Power Sour. 2006, 161, 702-706. [CrossRef]

48. Sampathkumar, L.; Selvin, P.C.; Selvasekarapandian, S.; Perumal, P.; Chitra, R.; Muthukrishnan, M. Synthesis and characterization of biopolymer electrolyte based on tamarind seed polysaccharide, lithium perchlorate and ethylene carbonate for electrochemical applications. Ionics 2019, 25, 1067-1082. [CrossRef]

49. Aziz, S.B.; Hamsan, M.H.; Kadir, M.F.Z.; Karim, W.O.; Abdullah, R.M. Development of Polymer Blend Electrolyte Membranes Based on Chitosan: Dextran with High Ion Transport Properties for EDLC Application. Int. J. Mol. Sci. 2019, 20, 3369. [CrossRef] 
50. Shuhaimi, N.E.A.; Teo, L.P.; Woo, H.J.; Majid, S.R.; Arof, A.K. Electrical double-layer capacitors with plasticized polymer electrolyte based on methyl cellulose. Polym. Bull. 2012, 69, 807-826. [CrossRef]

51. Virya, A.; Lian, K. Lithium polyacrylate-polyacrylamide blend as polymer electrolytes for solid-state electrochemical capacitors. Electrochem. Commun. 2018, 97, 77-81. [CrossRef]

52. Kadir, M.F.Z.; Arof, A.K. Application of PVA-chitosan blend polymer electrolyte membrane in electrical double layer capacitor. Mater. Res. Innov. 2011, 15, s217-s220. [CrossRef]

53. Lim, C.-S.; Teoh, K.H.; Liew, C.W.; Ramesh, S. Electric double layer capacitor based on activated carbon electrode and biodegradable composite polymer electrolyte. Ionics 2013, 20, 251-258. [CrossRef]

54. Liew, C.W.; Ramesh, S.; Arof, A.K. Enhanced capacitance of EDLCs (electrical double layer capacitors) based on ionic liquid-added polymer electrolytes. Energy 2016, 109, 546-556. [CrossRef]

55. Aziz, S.B.; Abdulwahid, R.T.; Hamsan, M.H.; Brza, M.A.; Abdullah, R.M.; Kadir, M.; Muzakir, S.K. Structural, Impedance, and EDLC Characteristics of Proton Conducting Chitosan-Based Polymer Blend Electrolytes with High Electrochemical Stability. Molecules 2019, 24, 3508. [CrossRef] [PubMed]

56. Aziz, S.B.; Brza, M.; Hamsan, M.; Kadir, M.; Muzakir, S.; Abdulwahid, R.T. Effect of ohmic-drop on electrochemical performance of EDLC fabricated from PVA: Dextran: NH4I based polymer blend electrolytes. J. Mater. Res. Technol. 2020, 9, 3734-3745. [CrossRef]

57. Selvakumar, M.; Bhat, D.K. Polyvinyl alcohol-polystyrene sulphonic acid blend electrolyte for supercapacitor application. Phys. B Condens. Matter 2009, 404, 1143-1147. [CrossRef]

58. Shukur, M.; Ithnin, R.; Kadir, M. Protonic Transport Analysis of Starch-Chitosan Blend Based Electrolytes and Application in Electrochemical Device. Mol. Cryst. Liq. Cryst. 2014, 603, 52-65. [CrossRef]

59. Arof, A.K.; Kufian, M.Z.; Shukur, M.; Aziz, M.F.; Abdelrahman, A.; Majid, S. Electrical double layer capacitor using poly (methyl methacrylate)-C4BO8Li gel polymer electrolyte and carbonaceous material from shells of mata kucing (Dimocarpus longan) fruit. Electrochim. Acta 2012, 74, 39-45. [CrossRef]

60. Yang, H.; Kannappan, S.; Pandian, A.S.; Jang, J.-H.; Lee, Y.S.; Lu, W. Graphene supercapacitor with both high power and energy density. Nanotechnology 2017, 28, 445401. [CrossRef]

61. Kadir, M.; Hamsan, M.H. Green electrolytes based on dextran-chitosan blend and the effect of NH4SCN as proton provider on the electrical response studies. Ionics 2017, 24, 2379-2398. [CrossRef]

62. Hamsan, M.H.; Shukur, M.; Kadir, M. The effect of NH4NO3 towards the conductivity enhancement and electrical behavior in methyl cellulose-starch blend based ionic conductors. Ionics 2016, 23, 1137-1154. [CrossRef]

63. Pesko, D.M.; Jung, Y.; Hasan, A.L.; Webb, M.A.; Coates, G.W.; Miller, T.F.; Balsara, N.P. Effect of monomer structure on ionic conductivity in a systematic set of polyester electrolytes. Solid State Ionics 2016, 289, 118-124. [CrossRef]

64. Hamsan, M.H.; Shukur, M.; Kadir, M. NH4NO3 as charge carrier contributor in glycerolized potato starch-methyl cellulose blend-based polymer electrolyte and the application in electrochemical double-layer capacitor. Ionics 2017, 23, 3429-3453. [CrossRef]

65. Liew, C.W.; Ramesh, S. Electrical, structural, thermal, and electrochemical properties of corn starch-based biopolymer electrolytes. Carbohydr. Polym. 2015, 124, 222-228. [CrossRef]

66. Asnawi, A.S.F.M.; Aziz, S.B.; Nofal, M.M.; Yusof, Y.M.; Brevik, I.; Hamsan, M.H.; Brza, M.A.; Abdilwahid, R.; Kadir, M. Metal Complex as a Novel Approach to Enhance the Amorphous Phase and Improve the EDLC Performance of Plasticized Proton Conducting Chitosan-Based Polymer Electrolyte. Membranes 2020, 10, 132. [CrossRef] [PubMed]

67. Asnawi, A.S.F.M.; Aziz, S.B.; Nofal, M.M.; Hamsan, M.H.; Brza, M.; Yusof, Y.M.; Abdilwahid, R.T.; Muzakir, S.K.; Kadir, M.F.Z. Glycerolized Li ${ }^{+}$Ion Conducting Chitosan-Based Polymer Electrolyte for Energy Storage EDLC Device Applications with Relatively High Energy Density. Polymers 2020, 12, 1433. [CrossRef] [PubMed]

68. Hamsan, M.; Aziz, S.B.; Azha, M.; Azli, A.; Shukur, M.; Yusof, Y.; Muzakir, S.; Manan, N.S.; Kadir, M. Solid-state double layer capacitors and protonic cell fabricated with dextran from Leuconostoc mesenteroides based green polymer electrolyte. Mater. Chem. Phys. 2020, 241, 122290. [CrossRef] 
69. Aziz, S.B.; Brza, M.; Mishra, K.; Hamsan, M.; Karim, W.O.; Abdullah, R.M.; Kadir, M.; Abdulwahid, R.T. Fabrication of high-performance energy storage EDLC device from proton conducting methylcellulose: Dextran polymer blend electrolytes. J. Mater. Res. Technol. 2020, 9, 1137-1150. [CrossRef]

70. Aziz, S.B.; Hamsan, M.H.; Karim, W.O.; Marif, A.S.; Abdulwahid, R.T.; Kadir, M.F.Z.; Brza, M.A. Study of impedance and solid-state double-layer capacitor behavior of proton $(\mathrm{H}+)$-conducting polymer blend electrolyte-based CS:PS polymers. Ionics 2020, 1-15. [CrossRef]

(C) 2020 by the authors. Licensee MDPI, Basel, Switzerland. This article is an open access article distributed under the terms and conditions of the Creative Commons Attribution (CC BY) license (http://creativecommons.org/licenses/by/4.0/). 